\title{
Generalization of instrumentally acquired pain-related avoidance to novel but similar movements using a robotic arm-reaching paradigm
}

Citation for published version (APA):

Glogan, E., Gatzounis, R., Meulders, M., \& Meulders, A. (2020). Generalization of instrumentally acquired pain-related avoidance to novel but similar movements using a robotic arm-reaching paradigm. Behaviour Research and Therapy, 124, [103525]. https://doi.org/10.1016/j.brat.2019.103525

Document status and date:

Published: 01/01/2020

DOI:

10.1016/j.brat.2019.103525

Document Version:

Publisher's PDF, also known as Version of record

Document license:

Taverne

Please check the document version of this publication:

- A submitted manuscript is the version of the article upon submission and before peer-review. There can be important differences between the submitted version and the official published version of record.

People interested in the research are advised to contact the author for the final version of the publication, or visit the DOI to the publisher's website.

- The final author version and the galley proof are versions of the publication after peer review.

- The final published version features the final layout of the paper including the volume, issue and page numbers.

Link to publication

\footnotetext{
General rights rights.

- You may freely distribute the URL identifying the publication in the public portal. please follow below link for the End User Agreement:

www.umlib.nl/taverne-license

Take down policy

If you believe that this document breaches copyright please contact us at:

repository@maastrichtuniversity.nl

providing details and we will investigate your claim.
}

Copyright and moral rights for the publications made accessible in the public portal are retained by the authors and/or other copyright owners and it is a condition of accessing publications that users recognise and abide by the legal requirements associated with these

- Users may download and print one copy of any publication from the public portal for the purpose of private study or research.

- You may not further distribute the material or use it for any profit-making activity or commercial gain

If the publication is distributed under the terms of Article 25fa of the Dutch Copyright Act, indicated by the "Taverne" license above, 


\title{
Generalization of instrumentally acquired pain-related avoidance to novel but similar movements using a robotic arm-reaching paradigm
}

\author{
Eveliina Glogan ${ }^{\mathrm{a}, \mathrm{b}}$, Rena Gatzounis ${ }^{\mathrm{a}}$, Michel Meulders ${ }^{\mathrm{c}, \mathrm{d}}$, Ann Meulders ${ }^{\mathrm{a}, \mathrm{b}, *}$ \\ ${ }^{\text {a }}$ Experimental Health Psychology, Maastricht University, Maastricht, the Netherlands \\ ${ }^{\mathrm{b}}$ Research Group Health Psychology, KU Leuven, Leuven, Belgium \\ ${ }^{c}$ Research Centre for Mathematics, Education, Econometrics and Statistics, KU Leuven, Brussels Campus, Belgium \\ ${ }^{\mathrm{d}}$ Research Group Quantitative Psychology and Individual Differences, KU Leuven, Leuven, Belgium
}

\section{A R T I C L E I N F O}

\section{Keywords:}

Avoidance behavior

Fear generalization

Avoidance generalization

Chronic pain

Operant conditioning

\begin{abstract}
A B S T R A C T
Avoidance is considered a key contributor to the development and maintenance of chronic pain disability, likely through its excessive generalization. This study investigated whether acquired avoidance behavior generalizes to novel but similar movements. Using a robotic arm, participants moved their arm from a starting to a target location via one of three possible movement trajectories. For the Experimental Group, the shortest, easiest trajectory was always paired with pain $(\mathrm{T} 1=100 \%$ reinforcement/no resistance and deviation). Pain could be partly or completely avoided by choosing increasingly effortful movements $(\mathrm{T} 2=50 \%$ reinforcement, moderate resistance/deviation; T3 $=0 \%$ reinforcement, strongest resistance/largest deviation). A Yoked Group received the same number of painful stimuli irrespective of their own behavior. Outcomes were self-reported fear of movement-related pain, pain-expectancy, avoidance behavior, (maximal deviation from the shortest trajectory), and trajectory choice behavior. We tested generalization to three novel trajectories (G1-3) positioned next to the acquisition trajectories. Whereas acquired fear of movement-related pain and pain-expectancy generalized in the Experimental Group, avoidance behavior did not, suggesting that threat beliefs and high-cost avoidance may not be directly related. The lack of avoidance generalization may be due to a perceived context-switch in the configurations of the acquisition and the generalization phases.
\end{abstract}

\section{Introduction}

Acute pain warns us of immediate or impending physical threat, and often dissipates once injury has healed. Chronic pain, on the other hand, persists even in the absence of evident physical damage, and thus ceases to be adaptive (IOM (Institute of Medicine), 2011; Treede et al., 2015). Further, chronic pain is a widespread health concern posing significant individual and societal burden (Breivik, Collett, Ventafridda, Cohen, \& Gallacher, 2006; Breivik, Eisenberg, O'Brien, \& Openminds, 2013; Gaskin \& Richard, 2012; Phillips, 2009), with calls being made to increase our knowledge of, and improve the quality of care for chronic pain (Breivik et al., 2013).

Pain-related fear and avoidance are considered to play a key role in the chronification of acute pain (Crombez, Eccleston, Van Damme, Vlaeyen, \& Karoly, 2012; Leeuw et al., 2007; Vlaeyen \& Linton, 2000, 2012). According to the fear-avoidance model of chronic pain, catastrophic misinterpretations of pain (e.g. pain representing re-injury or a catastrophe such as the spine snapping) may result in increased pain- related fear (Crombez et al., 2012; Leeuw et al., 2007; Vlaeyen \& Linton, 2000, 2012). To alleviate fear, individuals avoid movements and activities they believe will worsen their pain. Though avoidance is adaptive when pain is acute, in chronic pain it becomes maladaptive and can lead to functional disability, via disuse and decreased daily activity (Crombez et al., 2012; Leeuw et al., 2007; Vlaeyen \& Linton, 2000, 2012).

Fear of movement-related pain can be learned through classical conditioning (Meulders, Vansteenwegen, \& Vlaeyen, 2011; Meulders \& Vlaeyen, 2013; Vlaeyen, 2015). In a study with a voluntary joystick movement (VJM) paradigm (Meulders et al., 2011), participants performed joystick movements to the right and left. One of these movements (e.g. to the left; conditioned stimulus CS +) was associated with a painful electrocutaneous stimulus (unconditioned stimulus, US), whereas the other movement (e.g. to the right; CS-) was not. The $\mathrm{CS}+$ came to elicit higher conditioned responses (CRs; self-reported fear of movement-related pain, eye-blink startle responses, and movement latencies (a proxy measure of behavioral avoidance)), in

\footnotetext{
* Corresponding author. Faculty of Psychology and Educational Sciences, KU Leuven, Tiensestraat 102, box 3726, 3000, Leuven, Belgium.

E-mail address: ann.meulders@kuleuven.be (A. Meulders).
} 
comparison to the CS- (Meulders et al., 2011). In clinical terms, this might mean that a person who experiences shooting back pain (painUS) when bending forward (CS+) to lift their child, may come to associate bending forward with pain, and to consequently fear (CR) lifting their child in future situations.

Conditioned fear can spread to a range of stimuli or events related to the original fear experience - a phenomenon known as fear generalization (Dunsmoor, Mitroff, and LaBar, 2011; Dymond, Dunsmoor, Vervliet, Roche, \& Hermans, 2015; Grillon et al., 2013; Ghirlanda \& Enquist, 2003; Honig \& Urcuioli, 1981; Kalish, 1969; Lissek et al., 2008). Specifically, generalization stimuli (GSs) that are similar to the original fear-evoking stimulus, but never experienced in the presence of the US, can also come to trigger conditioned fear responses. Fear generalization is adaptive, as it minimizes the necessity to always learn anew. However, excessive fear generalization comes with the risk of fearful responding to false alarms (Dymond, Vervliet, \& Hermans, 2015; Lissek \& Grillon, 2010). For example, the fear associated with bending forward to pick up a child might spread to a range of other safe bending-related movements and activities (e.g. yoga or household chores).

Generalization of fear of movement-related pain has been demonstrated in the lab (Meulders, Vandebroek, Vervliet, \& Vlaeyen, 2013; Meulders \& Vlaeyen, 2013). For example, using the VJM paradigm, Meulders et al. (Meulders et al., 2013) found that intermediate movements between the CS + (GSs +) and CS- (GSs-) came to elicit eye-blink startle responses, which linearly decreased in intensity with decreasing similarity with the CS + (i.e. generalization gradient Dunsmoor, Mitroff, and LaBar, 2009; Greenberg, Carlson, Cha, Hajcak and Mujica-Parodi, 2013). Moreover, evidence suggests that chronic pain patients excessively generalize fear and expectancies of pain (Meulders, Harvie, Caragianis, \& Moseley, 2014; Meulders, Jans, \& Vlaeyen, 2015). For example, it was found that whereas healthy participants exhibited a clear generalization gradient, chronic hand pain patients showed flatter gradients with higher pain-expectancy towards GSs similar to the CS(Meulders et al., 2014). In another study, fibromyalgia patients showed less differential fear generalization between GSs + and GSs-, in comparison to healthy control participants (Meulders et al., 2015). These results suggest that chronic pain patients do not differentiate between safe and harmful stimuli as accurately as healthy individuals.

Although a considerable amount of research has been dedicated to understanding pain-related fear, pain-related avoidance behavior is largely unexplored. This is surprising given the central role of avoidance behavior in theoretical and clinical models of chronic pain disability (Crombez et al., 2012; Leeuw et al., 2007; Vlaeyen \& Linton, 2000, 2012); namely, where fear merely induces discomfort, avoidance behavior is a potential pathway to functional disability.

Avoidance behavior can be learned through operant conditioning, whereby a behavior that results in the omission of a negative event (e.g. pain) will be negatively reinforced, i.e. the likelihood of that behavior occurring again in the future is increased (Skinner, 1953). For example, the person who begins to fear bending movements after experiencing pain in the back may begin to avoid bending forward to prevent pain from occurring again (i.e. omission of a negative event). When the pain does not occur, he/she might (mis)attribute this outcome to avoidance behavior (even if in reality, the injury has simply healed), and persistently avoid bending forward. Given that fear can be accompanied by avoidance behavior, and also has the potential to generalize (excessively) (Dymond et al., 2015; Ghirlanda \& Enquist, 2003; Honig \& Urcuioli, 1981; Kalish, 1969), this person may also generalize his/her avoidance behavior, and begin to avoid a range of bending-related movements and activities, even if these are safe. This, in turn, may lead to decreased engagement in daily activity, ultimately resulting in chronic pain disability.

One reason for the scarcity of research on this clinically relevant but challenging topic is the a lack of valid paradigms to study avoidance behavior in humans (Krypotos, Vervliet, \& Engelhard, 2018). To address this problem, Meulders et al. (Meulders, Franssen, Fonteyne, \& Vlaeyen, 2016) developed a novel operant conditioning paradigm (robotic arm-reaching paradigm) to investigate pain-related avoidance behavior. In this paradigm, participants perform three different armreaching movements using a robotic arm. The movements differ in the effort they require, as well as their likelihood of being paired with a painful electrocutaneous stimulus. Specifically, the least effortful movement (in terms of distance and resistive force; T1) is always paired with pain, a moderately effortful one (T2) is paired with a $50 \%$ chance of receiving pain, and the most effortful trajectory (T3) is never paired with pain, in the Experimental Group. Thus, participants in the Experimental Group can avoid the painful stimulus, but have to exert more effort. A Yoked Group receives the same number of painful stimuli, irrespective of the movement trajectories they choose. Avoidance behavior is operationalized as the maximal deviation from the shortest trajectory. In the study of Meulders et al. (Meulders et al., 2016), selfreported fear of movement-related pain, and pain-expectancy reflected the experimental contingencies $(\mathrm{T} 1>\mathrm{T} 2>\mathrm{T} 3)$ in the Experimental Group, whereas there were no differences in ratings between trajectories in the Yoked Group. Furthermore, the Experimental Group showed more avoidance, that is, they showed larger deviations from the shortest trajectory, compared to the Yoked Group (Meulders et al., 2016).

In the current study, we extended the robotic arm-reaching paradigm (Meulders et al., 2016), to investigate whether acquired avoidance behavior would also generalize to novel movements that had never been paired with pain. To do this we included a generalization phase, during which three novel movement trajectories (generalization trajectories G1-3) were performed under extinction (intermixed with blocks where the original trajectories (T1-3) were performed, under reinforcement (reminder-of-acquisition)). Dependent measures were avoidance behavior, self-reported fear of movement-related pain-, and pain-expectancy ratings. We expected (1) to replicate acquisition of avoidance behavior, fear of movement-related pain, and pain-expectancy (Meulders et al., 2016), and crucially, (2) that acquired fear and avoidance would generalize to the novel movement trajectories, i.e. the Experimental Group would avoid more (show larger maximal deviation), compared to the Yoked Group, during the generalization phase, and fear of movement-related pain and pain-expectancy would vary along with the different trajectories (G1 > G2 > G3) in the Experimental Group. No such differences were expected in self-reports for the different trajectories in the Yoked Group.

\section{Methods and materials}

\subsection{Participants}

Sixty-four (sample size replicated from (Meulders et al., 2016)) healthy, pain-free volunteers participated in the study (42 females, mean $\pm S D$ age $=23 \pm 6$, range $=18-57)$. They were assigned either to the Experimental $(n=32)$ or to the Yoked $(n=32)$ Group, based on an alternating schedule depending on the order in which they arrived at the laboratory. The matching procedure was replicated from Meulders et al. (Meulders et al., 2016). We did not match participants based on gender, and given the general homogeneity in age in the student population from which we recruited, we did not deem it necessary to explicitly match participants based on age. Participants were recruited by the experimenter (EG) through the research participation system of Maastricht University (Sona; Sona Systems, Nijmegen, The Netherlands), as well as advertisements distributed around the university campus, and through social media. Recruitment and data collection took place during May and June of 2018. Exclusion criteria comprised chronic pain; analphabetism or diagnosed dyslexia; pregnancy; lefthandedness; current/history of cardiovascular disease; chronic or acute respiratory disease (e.g., asthma, bronchitis); neurological disease (e.g., epilepsy); current/history of psychiatric disorder (e.g., clinical 
depression, panic/anxiety disorder); uncorrected problems with hearing or vision; having pain at the dominant hand, wrist, elbow or shoulder that may hinder performing the reaching task; presence of implanted electronic medical devices (e.g., cardiac pacemaker); and presence of any other severe medical conditions. All participants completed an exclusion criteria checklist, and provided informed consent. Participants were informed that they could freely terminate participation at any time without any negative consequences. Participants received either 1.5 course credit, or $€ 12.50$ in gift vouchers. The study was approved by the Ethics Review Committee Psychology and Neuroscience of Maastricht University (registration number: 1850911 2017 S1).

\subsection{Apparatus and stimulus material}

\subsubsection{HapticMaster}

The HapticMaster (HM; Motekforce Link, Amsterdam, the Netherlands) is a 3 degrees-of-freedom force-controlled robotic arm. More specifically, it is an admittance-controlled robot, which means that when the individual exerts a certain force, the device reacts with a corresponding movement. The volumetric workspace of the HM consists of a depth of $0.36 \mathrm{~m}$, a height of $0.40 \mathrm{~m}$, and a width of $1 \mathrm{~m}$. In the current experiment, movements were confined to a 2-dimensional horizontal movement plane with a depth of $0.36 \mathrm{~m}$ and a width of $0.41 \mathrm{~m}$. The HM records exerted force, velocity, and positions of displacement over time during a movement. This information can be fed back to other devices, and used as input to trigger other stimulus presentations. In the current study, information about participants' movements was used to correctly time presentations of the painful electrocutaneous stimulus.

\subsubsection{Software and hardware}

The experiment was programmed in C\#, using the cross-platform game engine Unity 2017 (Unity Technologies, San Francisco, CA, USA), and 3D graphics software Blender 2.79 (Blender Foundation, Amsterdam, The Netherlands). Communication with the HM took place via a direct application programming interface (API) connection using the specific IP address and port number of the HM. The experiment was run on a Windows 10 Enterprise (Microsoft Corporation, Redmond, WA, USA) 64-bit Intel Core desktop computer (Intel Corporation, Santa Clara, CA, USA) with 8 GB RAM, CPU: i7-7700 at $3.600 \mathrm{GHz}$, and presented on a 40-inch LCD screen (Samsung UE40ES5500; Samsung Group, Seoul, South Korea).

\subsubsection{Painful electrocutaneous stimulus}

The painful stimulus ("pain") was an electrocutaneous stimulus (square-wave, $2 \mathrm{~ms}$ duration), delivered by a commercial constant current stimulator (DS7A; Digitimer, Welwyn Garden City, United Kingdom), through two reusable stainless steel disk electrodes $(8 \mathrm{~mm}$ diameter with $30 \mathrm{~mm}$ spacing; Digitimer, Welwyn Garden City, United Kingdom) filled with K-Y gel (Reckitt Benckiser, Slough, United Kingdom), and attached around the triceps tendon of the right (dominant) arm, using a Velcro strap. In order to increase spatial contiguity of the movement and the pain, the electrodes were attached to the right arm, with which the task was performed.

\subsection{Protocol}

The session lasted approximately $1.5 \mathrm{~h}$, during which participants were tested individually. Participants were informed that the experiment involved the presentation of painful electrocutaneous stimuli. After completion of exclusion criteria- and informed consent forms, the experimenter attached the electrodes, the pain calibration procedure was carried out (see '2.3.1. Calibration of the painful stimulus'), and participants completed the task (see '2.3.2. Robotic arm-reaching task'). After completing the task, participants filled in an exit questionnaire and six psychological trait questionnaires (see '2.5.2. Exit questionnaires' and '2.5.3. Psychological trait questionnaires'), after which they were thanked for their participation, received the compensation of choice, and were dismissed.

\subsubsection{Calibration of the painful stimulus}

Intensity of the pain was individually calibrated for each participant. Participants were administered a series of electrocutaneous stimuli, starting with an intensity of $1 \mathrm{~mA}$ and increasing stepwise. They were asked to rate each electrocutaneous stimulus on a numerical scale ranging from 0 to 10, where 0 was labelled as "I feel nothing"; 1 as "I feel something, but this is not unpleasant; it is only a sensation", 2 as "the stimulus is not yet painful, but is beginning to be unpleasant"; and 10 as "this is the worst pain I can imagine" (e.g. (Meulders et al., 2013; Meulders \& Vlaeyen, 2013),). Participants were asked to select a stimulus that they would describe as "significantly painful and demanding some effort to tolerate". The mean physical intensity of the electrocutaneous stimulus chosen during the calibration procedure was $34.5 \mathrm{~mA}( \pm S D=21.6$, range $=4-99$ ), and the mean self-reported stimulus intensity was 7.8 $( \pm S D=0.76$, range $=5-9$ ).

\subsubsection{Robotic arm-reaching task}

The robotic arm-reaching task was adapted from Meulders et al. (Meulders et al., 2016). Participants were seated in a chair, at an approximate distance of $2.5 \mathrm{~m}$ from the LCD screen, and a comfortable distance $(\sim 15 \mathrm{~cm})$ from the handle (sensor) of the HM. Participants were required to hold the sensor of the HM in their right hand, and to move it from a starting location to a target location. Feedback regarding movements performed within the experimental movement plane was provided visually on the LCD screen (see Fig. 1, panel 2 for a flow-chart of the experimental task). The sensor was visualized on the screen as a "green ball", which allowed participants to track their movements onscreen. The start and target locations were situated at the lower and upper left corners of the movement plane, respectively. The target location was visualized as a green arch, through which the green ball had to pass in order for the movement to be completed. Participants could reach the target via three different movement trajectories (T1-3) represented on screen as three arches situated midway through the movement plane. The trajectory arches were separated, in order to leave room for the generalization trajectory arches, which were positioned next to the acquisition trajectory arches during the generalization phase (G1-3, see Fig. 1, panel 2, "Generalization"). The trajectory arches, as well as the target arch, each had their own counter, which increased by 1 unit when the green ball had successfully passed through the corresponding arch; the given trajectory counter was set back to 0 once the target was successfully reached, and the target counter increased by 1 unit. On each trial, participants freely chose one of the three movement trajectories to reach the target location.

To indicate that the participant could initiate the movement, the target arch and a "traffic light" positioned at the top of the movement plane, turned green, and an auditory "starting signal" was presented (Fig. 1). A movement was successfully completed when (1) the green ball passed through the target arch at the end of the movement plane, (2) the overall trial counter placed next to the target arch increased by 1 unit, (3) an auditory "scoring signal" was presented, and (4) both the target arch and traffic light turned red. Upon successful movement completion, participants were required to release the HM, which repositioned itself to the starting position automatically. While the HM was repositioning, the target arch and traffic light remained red, indicating that moving the HM was prohibited at that point. After returning to its starting position, the HM remained fixed for 3s (inter-trial interval; ITI) before the start of the next trial.

The HM was programmed such that there was a linear relationship between resistive force and the lateral displacement of the robotic arm. This means that, when the shortest trajectory (T1) was chosen, minimal effort was needed to reach the target (in terms of distance and resistive 

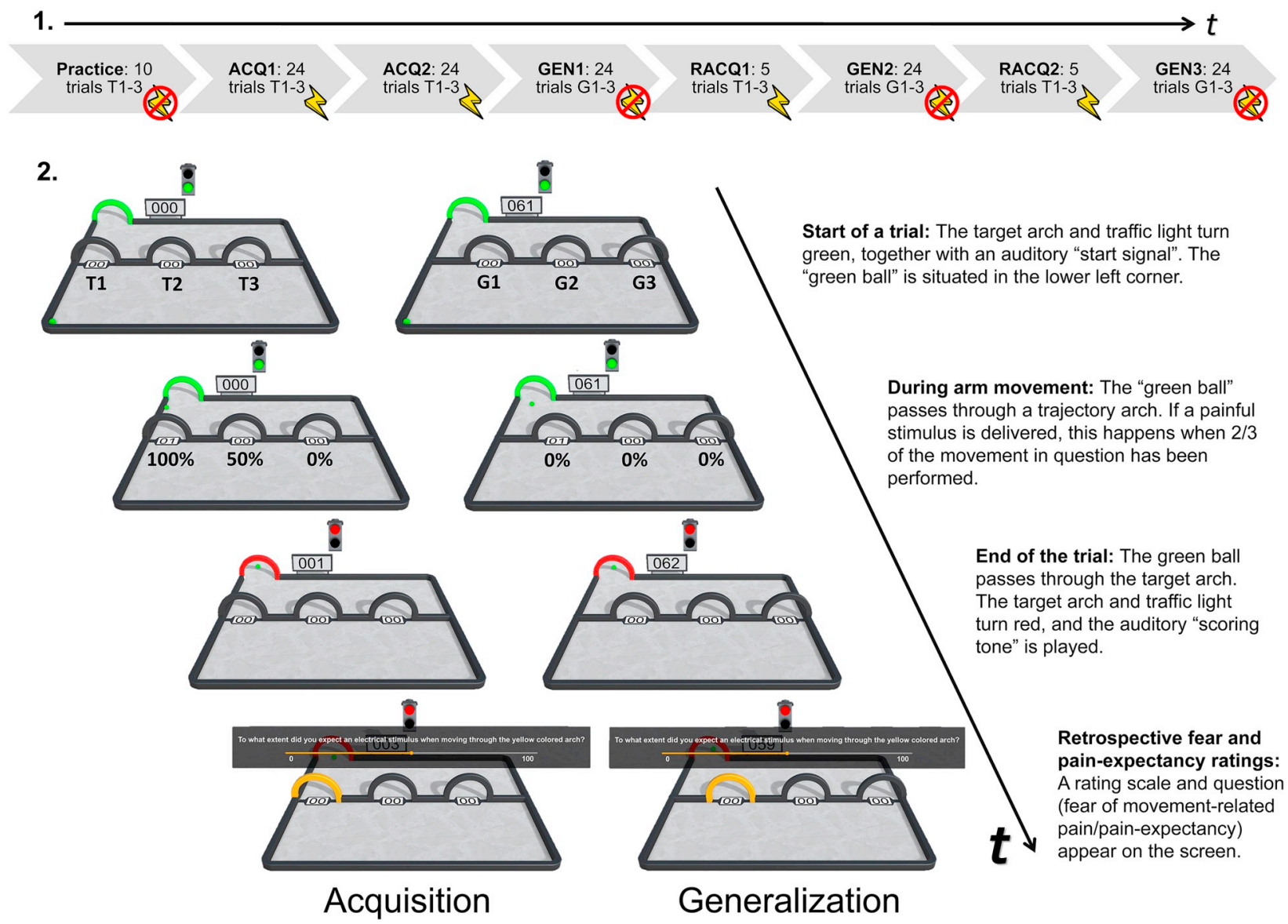

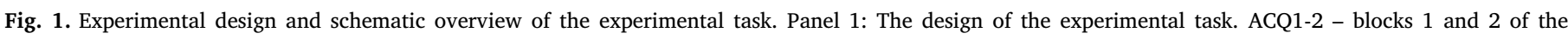

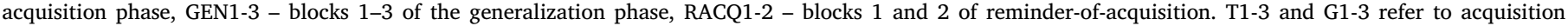

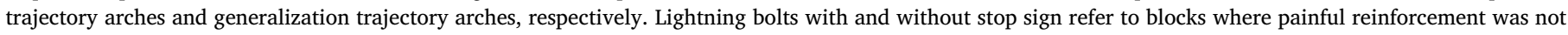

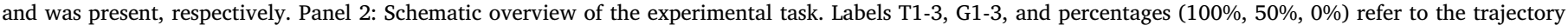

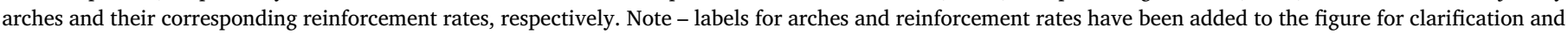
were not part of the visual representation of the experimental paradigm.

force), when the middle trajectory (T2) was chosen, moderate effort was needed, and when the target was reached via the longest trajectory (T3), the most effort was needed to reach the target. Participants completed four phases: the practice phase, the acquisition phase, and the generalization phase that was interspersed by short reminder-ofacquisition blocks (Fig. 1, panel 1.).

Practice phase. Participants read on-screen instructions about the task and then performed 10 practice trials, during which the participant was trained to operate the HM correctly. The first trial was performed by the experimenter as an example, after which the participant was asked to try each trajectory a few times. Only acquisition trajectory arches (T1-3) were shown during the practice phase. During this phase, the experimenter also ensured that participants did not start moving before the starting signals were presented, and that they released the HM immediately when the scoring signal appeared. Participants were also trained to provide self-report measures (see '2.4.2 Self-reports: fear of movement-related pain and pain-expectancy') using a Windows 10 compatible triple foot switch (USB-3FS-2; Tokyo, Japan). A foot switch instead of a manual switch was used in order to not interfere with the arm-reaching movements. During this phase, no painful stimuli were presented, but the above-mentioned relationship between the resistive force and lateral displacement of the HM was already in operation.

Acquisition. The acquisition phase consisted of 2 blocks of 24 trials. For participants in the Experimental Group, the easiest and shortest trajectory was always paired with the pain $(\mathrm{T} 1=100 \%$ reinforcement; no resistance or deviation) (Fig. 1). The pain was delivered when $2 / 3$ of the movement was completed. By choosing one of the other trajectories, participants were able to either partly ( $\mathrm{T} 2=50 \%$ reinforcement; moderate resistance and deviation) or completely ( $\mathrm{T} 3=0 \%$ reinforcement; strongest resistance and largest deviation) avoid the pain, but more effort was required. Each participant in the Yoked Group was matched to a participant in the Experimental Group, meaning that they received pain on the same trials as their Experimental Group counterpart, irrespective of their chosen movement trajectory. For example, if a participant in the Experimental Group chose T1 on trial 14 of the acquisition phase, and thus received pain on that trial, his/her yoked control also received pain on trial 14, even if (s)he chose T3. During the acquisition phase, fear of movement-related pain, and pain-expectancy for all trajectories were assessed three times during each block. Pain intensity and unpleasantness ratings were collected at the end of each block.

Generalization. This phase was similar to the acquisition phase, except that (1) there were 3 blocks of 24 trials, (2) no painful stimuli were delivered, and, critically, (3) three novel trajectories were available (G1-3; generalization trajectories) instead of T1-3. G1 was positioned between T1 and T2, G2 was positioned between T2 and T3, and G3 was positioned to the right of T3 (see Fig. 1, panel 2, "Generalization"). Thus, G1 was similar to both pain-associated trajectories (T1 and T2). G2 represented an ambiguous trajectory, as it was between a trajectory partially associated with pain, and a safe trajectory. G3 represented "overgeneralization" of avoidance behavior, as performing this movement required more effort than performing the movement that 
previously completely averted the pain. Again, retrospective fear of movement-related pain, and pain-expectancy questions were asked three times during each block of the generalization phase. The generalization phase was identical for both groups and was interspersed with brief reminder-of-acquisition blocks (see 'Reminder-of-acquisition').

Reminder-of-acquisition. In order to prevent extinction during the generalization phase, the three blocks of generalization were interspersed with two brief reminder-of-acquisition blocks, during which the acquisition trajectories were once again available along with the related contingencies. These blocks comprised 5 trials. Fear of movement-related pain, and pain-expectancy questions were asked once in the middle of both reminder-of-acquisition blocks.

\subsection{Primary outcome measures}

\subsubsection{Behavioral avoidance}

Avoidance behavior was operationalized as the maximal deviation from the shortest trajectory, from the start location to the target location, on each trial of the robotic arm-reaching task. This information was extracted using the co-ordinates of each performed movement, which were automatically logged by the HM.

\subsubsection{Self-reports: retrospective pain-expectancy and fear of movement- related pain}

During the acquisition and generalization phases, fear of movementrelated pain and pain-expectancy reports were collected three times for each trajectory during each block on fixed, predefined trials. During the shorter reminder-of-acquisition blocks, reports were collected once for each trajectory. Questions were presented on-screen. To indicate the movement trajectory to which the question was referring to, the corresponding arch turned yellow (Fig. 1). Participants rated the questions "To what extent did you expect an electrical stimulus when moving through the yellow-colored arch?" (i.e. pain-expectancy) and "How afraid were you to move through the yellow-colored arch?" (i.e. fear of movementrelated pain) retrospectively for each of the movement trajectories. Answers were provided on a Visual Analogue Scale (VAS) ranging from 0 to $100(0=$ "not at all" and $100=$ "very much"), using the foot pedals. The left and middle foot pedals were used to scroll to the left and right on the rating scale, respectively, and the right foot pedal was used to confirm the participant's answer. During the time that participants responded to these questions, the HM was immobilized.

\subsection{Secondary outcome measures}

\subsubsection{Trajectory choice}

Frequencies of choices for all movement trajectories were calculated for both groups. This information was automatically logged by the HM.

\subsubsection{Exit questionnaire}

Immediately after completing the robotic arm-reaching task, participants completed an exit questionnaire, which included the following questions: (1) "How intense did you find the electrical stimulus during the robotic arm task?", (2) "How unpleasant did you find the electrical stimulus?", (3) "How much did you want to avoid the electrical stimulus?", (4) "How threatening did you find the electrical stimulus?" (5) "How intense did you find the resistance of the robotic arm?", (6) "How unpleasant did you find the resistance?", and (7) "How much did you want to avoid the resistance?". These questions were responded to on an 11-point scale ranging from 0 to $10(0=$ not at all, and $10=$ very much). Furthermore, participants responded to contingency-awareness questions inquiring which arches they believed to be paired with the least and most resistance, and which arches they believed were least and most likely to predict the pain.

\subsubsection{Psychological trait questionnaires}

Participants completed six psychological questionnaires to measure individual differences in (1) positive and negative affect (PANAS; the Positive and Negative Affect Schedule [(Engelen, Peuter, Victoir, Diest, \& Van den Bergh, 2006; Watson, Clark, \& Tellegen, 1988)]), (2) pain catastrophizing (PCS; Pain Catastrophizing Scale [(Sullivan, Bishop, \& Pivik, 1995)]), (3) fear of pain (FPQ; Fear of Pain Questionnaire [(McNeil \& Rainwater, 1998; Roelofs, Peters, Deutz, Spijker, \& Vlaeyen, 2005)]), (4) experiential avoidance (MEAQ; the Multidimensional Experiential Avoidance Questionnaire [(Gamez, Chmielewski, Kotov, Ruggero, \& Watson, 2011)]), and (5) distress tolerance (DTS; the Distress Tolerance Scale [(Simons \& Gaher, 2005)]). Questionnaires were presented using a web survey tool (Qualtrics; Qualtrics, Provo, Utah, USA; Seattle, Washington, USA), and completed on a tablet (ASUS ZenPad 8.0, AsusTek Computer Inc., Taipei, Taiwan).

\subsection{Statistical analysis overview}

Paired samples $t$-tests between groups were performed on sample characteristics data (age, physical pain intensity (in $\mathrm{mA}$ ), self-reported pain intensity, and scores of the psychological trait questionnaires), as well as exit questionnaire data. The acquisition phase was included in the analysis as a manipulation check, since acquisition of avoidance behavior, fear of movement-related pain and pain-expectancy are required to test for generalization effects. The reminder-of-acquisition phase was also analyzed as a manipulation check, given that its function was to refresh the originally acquired fear and avoidance responses. To test the hypothesis that self-report measures would differ significantly between the different trajectories (T1 $>\mathrm{T} 2>\mathrm{T} 3$; G1 > G2 > G3), in the Experimental but not the Yoked Group, responses were averaged over blocks, and repeated measures (RM) Analyses of Variance (ANOVAs) with "Group" as the between-subjects factor, and "Block" and "Trajectory" as the within-subjects factors, were performed on the mean fear of movement-related pain, and mean painexpectancy reports, respectively, and separately for each experimental phase. For analyses of avoidance behavior, maximum deviation from the shortest trajectory on each trial was calculated using a MatLab (MathWorks, Natick, MA, US) script. Furthermore, to increase comparability of avoidance data between the acquisition and generalization phases, the deviation data from the generalization phase were linearly transformed to share the same co-ordinates as the acquisition data. These values were averaged for each participant over each block. To compare avoidance behavior between groups, separate RM ANOVAs were performed with "Group" as the between-subjects factor, and "Block" as the within-subjects factor, separately for each phase. For all measures, we expected the largest generalization effects during the first generalization block, and for these to gradually decrease. Furthermore, as an exploratory analysis to investigate the effect of group on trajectory choice, we ran multinomial ordered logistic regression analyses for each experimental phase separately, with Trajectory Choice (T1-3/G13 ) as the ordered categorical dependent variable, and Group, Block, and the Group $x$ Block interaction as predictors. Specifically, for each experimental phase, a model including a normally distributed random shift effect to account for the dependence between observations within participants was estimated. The model consisted of two simultaneously estimated cumulative logit models. The first logit modelled the probability of choosing T/G3, and the second logit modelled the probability of choosing T/G2 or higher. The proportional odds assumption implies that the coefficients of the predictors (and hence the corresponding odds) are assumed to be equal in the two logit equations. For a detailed description of the model(s) (see Appendix 1). The $\alpha$ level was set at .05. To control for violations of sphericity, Greenhouse-Geisser corrections were applied when necessary. To control for multiple comparison testing, Bonferroni-Holm corrections were applied to all planned comparisons, and Bonferroni corrections to multiple independent samples $t$ tests. Pooled (Welch-Satterthwaite) degrees of freedom, and corrected $p$-values are reported. The indication of effect size $\eta_{p}^{2}$ is reported for 


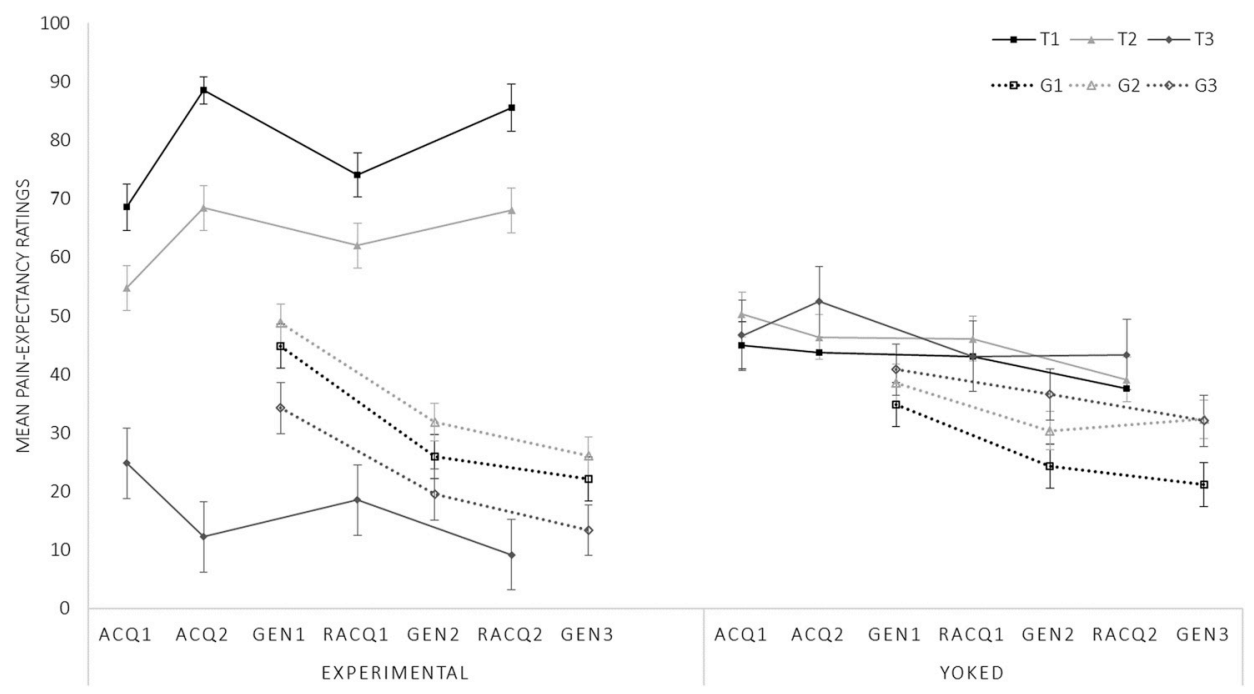

Fig. 2. Mean pain-expectancy towards the acquisition trajectories (T1-3) and generalization trajectories (G1-3) in the Experimental and Yoked Groups during the acquisition blocks (ACQ1-2), generalization blocks (GEN1-3), and reminder-of-acquisition blocks (RACQ1-2). Error bars represent SEM.

significant ANOVA effects, and Cohen's $d$ for planned comparisons. RM ANOVAs and planned comparisons were performed using the free software environment RStudio (RStudio Inc. Boston, MA, USA). Exploratory multinomial logistic regressions were estimated using the GLIMMIX Procedure in the statistical software SAS (SAS Institute Inc., Cary, NC, USA).

\section{Results}

\subsection{Sample demographics and characteristics of the painful stimulus and questionnaires}

There were no differences between the Experimental and Yoked Groups in age, $t(62)=0.37, p=.71$, chosen physical pain intensity, $t$ $(62)=0.65, p=.52$, or self-reported intensity of the painful stimulus, $t$ $(62)=1.07, p=.29$. In Table S1 in the supplementary materials, an overview is given of the questionnaire scores per group. There was a significant difference between groups in the minor-pain subscale of the FPQ, $t(62)=2.21, p=.03$. However, following Bonferroni correction, this difference was no longer significant $(\mathrm{p}>$.003). No other group differences emerged with regard to the psychological trait questionnaires (all $p$-values $>$.05).

\subsection{Manipulation checks}

\subsubsection{Acquisition}

3.2.1.1. Self-reported pain-expectancy. A 2 × 2 × 3 RM ANOVA (Group: Experimental, Yoked) x (Block: ACQ1-2) x (Trajectory: T1-3) revealed a significant main effect of Block, $F(1,62)=4.89, p<.05, \eta_{p}^{2}=0.07$, and Trajectory, $F(1.87,116.19)=63.4, p<.0001, \eta_{p}^{2}=0.51$. These were qualified by a significant three-way interaction, $F(1.97$, $121.91)=21.21, p<.0001, \eta_{p}^{2}=0.25$, suggesting that painexpectancies for the different trajectories changed differently in the two groups over time. Planned comparisons showed that by the end of the acquisition phase (ACQ2), the Experimental Group expected the pain stimulus to occur more when performing T1 compared to T3, $t$ $(31)=17.71, p<.0001, d=4.50$, and compared to T2, $t$ $(31)=4.67, p<.0001, d=1.19$ (see Fig. 2). In line with our hypothesis, pain-expectancy reports were also significantly higher for T2 compared to T3, $t(31)=13.04, p<.0001, d=3.31$. No such differences occurred in the Yoked Group (all $p$-values $>.05$ ). These results confirm that participants in the Experimental Group successfully acquired the experimental response-outcome contingencies.
3.2.1.2. Self-reported fear of movement-related pain. We performed a similar $2 \times 2 \times 3$ RM ANOVA on the fear ratings during the acquisition phase. This analysis yielded significant main effects for Block, $F(1$, $62)=16.25, p<.001, \eta_{p}^{2}=0.21$, and Trajectory, $F(1.5$, 93.27) $=28.79, p<.0001, \eta_{p}^{2}=0.32$. A significant three-way interaction emerged, $F(1.84,113.97)=10.74, p<.0001, \eta_{p}^{2}=0.15$, suggesting that fear of the respective trajectories evolved differently for the two groups during the acquisition phase. Planned comparisons confirmed that by the end of the acquisition phase (ACQ2), the Experimental Group was more afraid to perform $\mathrm{T} 1, t(31)=11.8$, $p<.0001, d=3$, and T2, $t(31)=11.02, p<.0001, d=2.80$, compared to T3. In contrast with the findings in the pain-expectancy ratings, no difference in fear ratings was observed between trajectories $\mathrm{T} 1$ and $\mathrm{T} 2, t(31)=0.78, p=.44$ (see Fig. 3 ), despite $\mathrm{T} 1$ having a higher probability to be followed by a painful stimulus than T2. None of these planned comparisons were significant in the Yoked Group (all $p$ values $>$.05). These findings corroborate the pain-expectancy results for T3, that is, this trajectory was perceived as safe, and consequently, performing this trajectory evoked less fear than the other trajectories (T1-2). In contrast, a discrepancy was observed between painexpectancy ratings and fear ratings for $\mathrm{T} 1$ and $\mathrm{T} 2$; although these trajectories elicited differential pain-expectancy ratings $(\mathrm{T} 1>\mathrm{T} 2)$, they produced similar levels of fear $(\mathrm{T} 1=\mathrm{T} 2)$.

3.2.1.3. Behavioral avoidance. A $2 \quad x \quad x \quad 2 \quad$ RM ANOVA (Group: Experimental, Yoked) x 2 (Block: ACQ1-2) was carried out on the maximal deviation data during acquisition. ${ }^{1}$ There was a significant main effect of Group, $F(1,62)=60.18, p<.0001, \eta_{p}^{2}=0.49$, and of Block, $F(1,62)=7.13, p<.05, \eta_{p}^{2}=0.10$, which were accommodated by a significant Group $\mathrm{x}$ Block interaction, $F(1$, $62)=20.55, p<.0001, \eta_{p}^{2}=0.25$. Planned comparisons confirmed that participants in the Experimental Group showed significantly larger deviations than the Yoked Group, during the second block of the acquisition phase, $t(62)=8.97, p<.0001$, $d=2.28$ (see Fig. 4). These findings confirm that participants in the Experimental Group acquired avoidance behavior whereas participants in the Yoked Group did not.

3.2.1.4. Trajectory choice. During the first block of the acquisition

\footnotetext{
${ }^{1}$ Trial-wise analyses were also run for the sake of completeness. However, these analyses did not yield differing results from the block-wise analysis.
} 


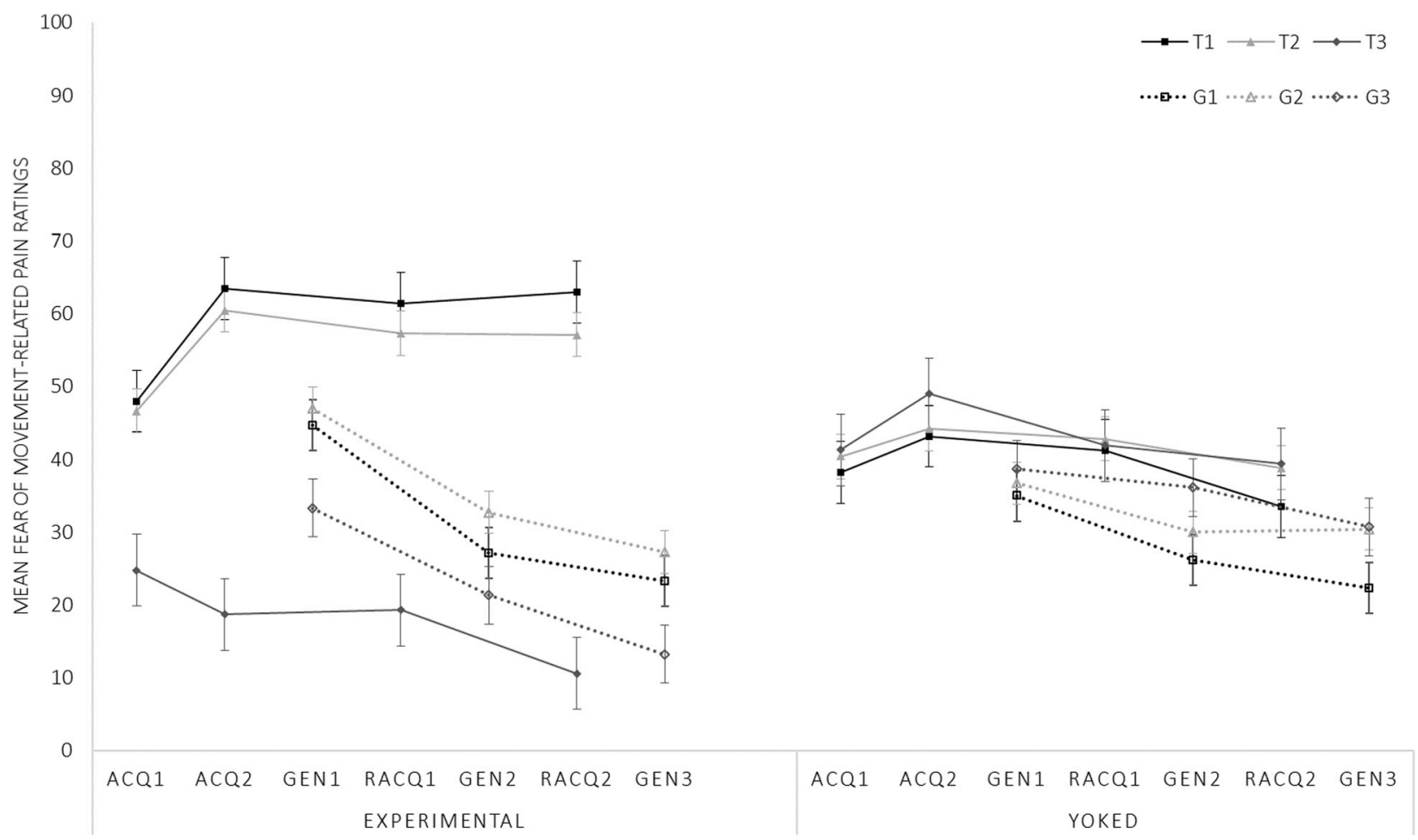

Fig. 3. Mean fear of movement-related pain towards the acquisition trajectories (T1-3) and generalization trajectories (G1-3) in the Experimental and Yoked Groups during the acquisition blocks (ACQ1-2), generalization blocks (GEN1-3), and reminder-of-acquisition blocks (RACQ1-2). Error bars represent SEM.

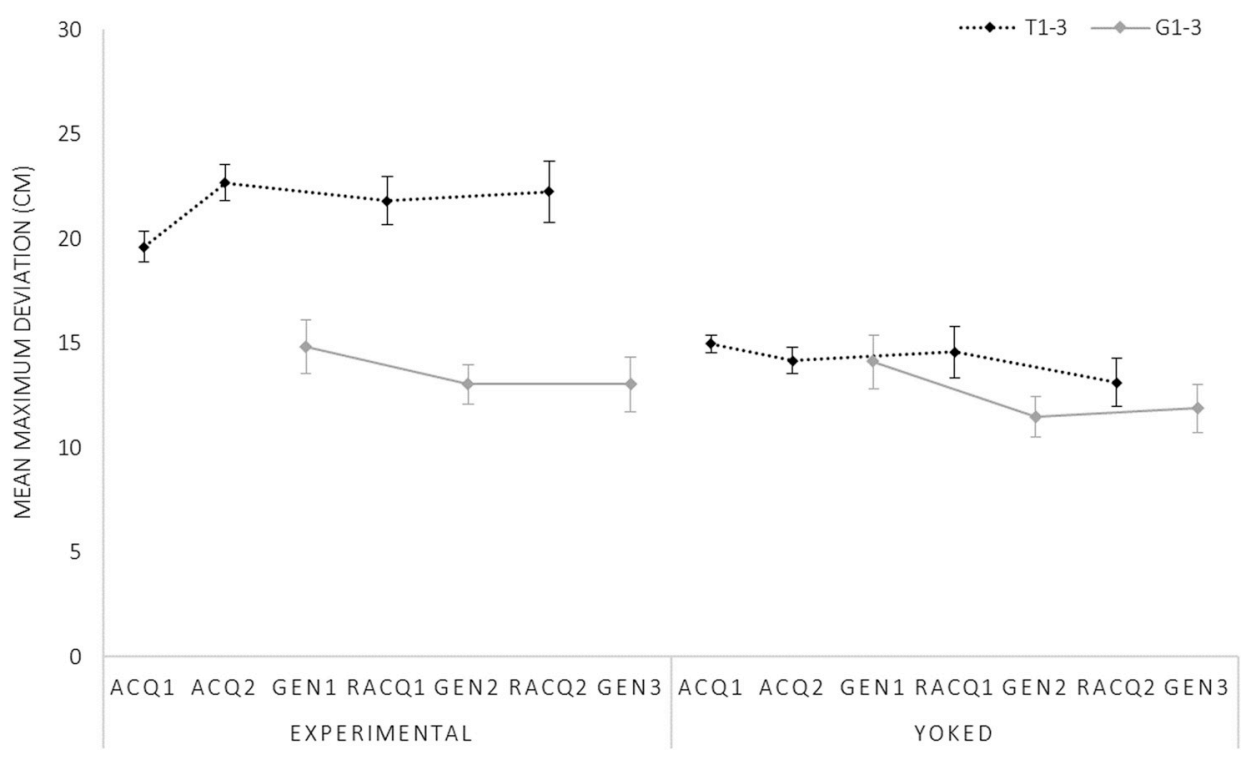

Fig. 4. Mean maximum deviation from the shortest trajectory from the starting position to the target during acquisition (ACQ1-2), generalization (GEN1-3), and reminder-of-acquisition (RACQ1-2), in the Experimental and Yoked Groups. Error bars represent SEM. Note - To increase comparability between phases, deviation data from the generalization phase have been linearly transformed to share the same coordinates as the acquisition data.

phase, participants in the Experimental Group were 2.42 times more likely to choose $\mathrm{T} 3$ rather than $\mathrm{T} 1$ or T2 (or, T3 or T2 rather than T1) than participants in the Yoked Group, $\left(\exp \left(\hat{\beta}_{\mathrm{G}}\right), p<.001\right.$, for $\hat{\beta}$ values see Table 1; see Fig. 5). During the second acquisition block, Experimental Group participants were 5.30 times more likely to choose $\mathrm{T} 3$ compared to $\mathrm{T} 1$ and $\mathrm{T} 2$ (or, $\mathrm{T} 3$ or $\mathrm{T} 2$ rather than $\mathrm{T} 1$ ) compared to participants in the Yoked Group, $\left(\exp \left(\hat{\beta}_{\mathrm{G}}+\hat{\beta}_{\mathrm{GxB} 2}\right)\right.$, $p<.001)$. A significant Group $\mathrm{x}$ Block interaction emerged, showing that the odds ratio of the Experimental Group, for choosing T3 rather than T1 or T2 (respectively T3 or T2 rather than T1), compared to the Yoked Group, was significantly higher during the second block of the acquisition phase, than during the first block of the acquisition phase (5.30 versus $2.42, p<.001$ ). Thus, compared to the Yoked Group, the propensity of Experimental Group participants to choose the avoidance trajectory, increased from the first acquisition block to the second acquisition block, suggesting that avoidance behavior was gradually acquired.

\subsubsection{Reminder-of-acquisition}

3.2.2.1. Self-reported pain-expectancy. A 2 × 2 × 3 RM ANOVA (Group: Experimental, Yoked) x (Block: RACQ1-2) x (Trajectory: T1-3) revealed a significant main effect of Group, $F(1,62)=5.64, p<.05, \eta_{p}^{2}$ $=0.08$, and of Trajectory, $F(1.67,103.43)=80.68, p<.0001, \eta_{p}^{2}$ $=0.57$. These were accommodated by a significant Group x Block $\mathrm{x}$ Trajectory interaction, $F(1.76,108.83)=12.51, p<.0001, \eta_{p}^{2}$ $=0.17$, suggesting that pain-expectancy towards the different trajectories evolved differently in both groups during the reminder-of- 
Table 1

Regression coefficients $(\hat{\beta})$ and odds $(\exp (\hat{\beta}))$ for the variables included in the random proportional odds models for the different experimental phases.

\begin{tabular}{|c|c|c|c|c|c|c|c|}
\hline & & \multicolumn{2}{|l|}{ Acquisition } & \multicolumn{2}{|c|}{ Reminder-of-acquisition } & \multicolumn{2}{|c|}{ Generalization } \\
\hline & & $\hat{\beta}$ & $\exp (\hat{\beta})$ & $\hat{\beta}$ & $\exp (\hat{\beta})$ & $\hat{\beta}$ & $\exp (\hat{\beta})$ \\
\hline Intercept T3/G3 & $\alpha_{3}$ & $-1.071^{* * *}$ & 0.34 & $-1.342^{* * *}$ & 0.26 & $-1.487^{* * *}$ & 0.23 \\
\hline Intercept T2/G2 & $\alpha_{2}$ & $.548^{* * *}$ & 1.73 & .352 & 1.42 & -.008 & 0.99 \\
\hline Group & $\beta_{\mathrm{G}}$ & $.885^{* * *}$ & 2.42 & $1.603^{* * *}$ & 4.97 & .451 & 1.57 \\
\hline Block 2 & $\beta_{B 2}$ & -.171 & 0.84 & -.262 & 0.77 & $-.584 * * *$ & 0.56 \\
\hline Block 3 & $\beta_{B 3}$ & & & & & $-.524 * * *$ & .59 \\
\hline Group x Block 2 & $\beta_{\mathrm{GxB} 2}$ & $.783^{* * *}$ & 2.19 & .363 & 1.44 & .181 & 1.20 \\
\hline Group x Block 3 & $\beta_{\mathrm{GxB} 3}$ & & & & & .125 & 1.13 \\
\hline
\end{tabular}

* = significant at .05 .

$* *=$ significant at .01 .

$* * *=$ significant at .001

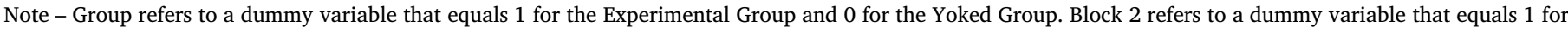
Block 2, and 0 in other cases. Block 3 refers to dummy variable that equals 1 for Block 3, and 0 in other cases.

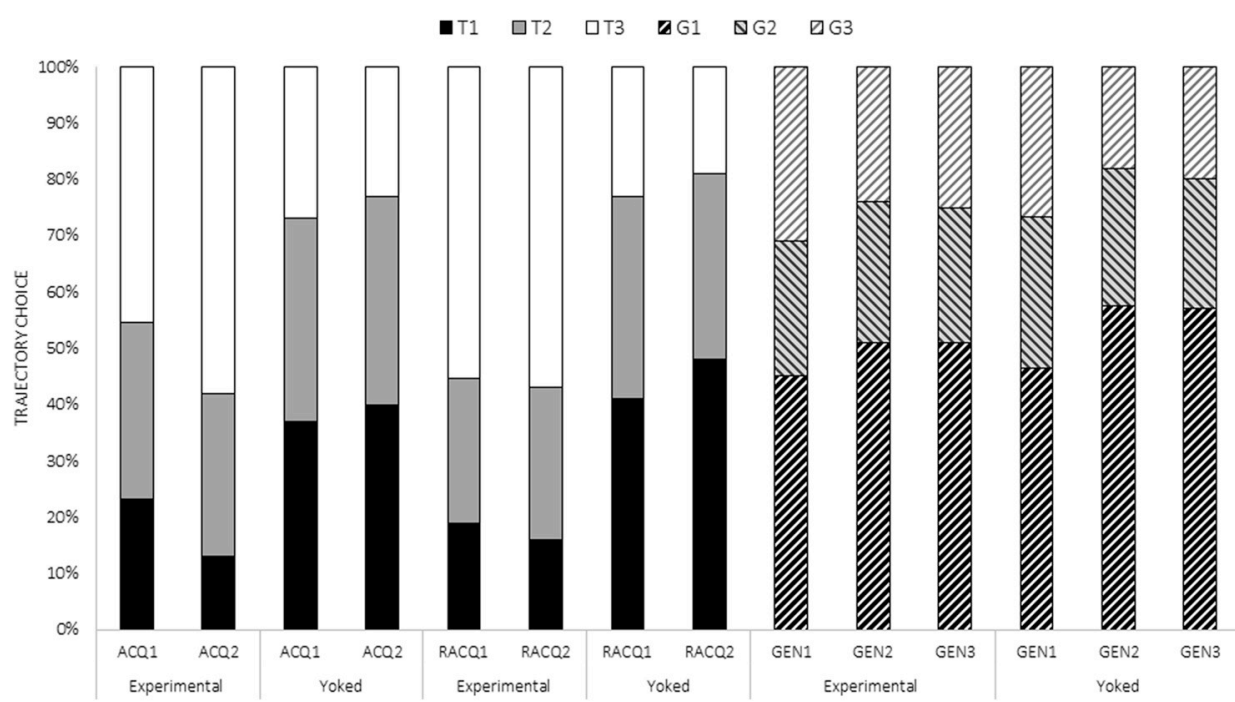

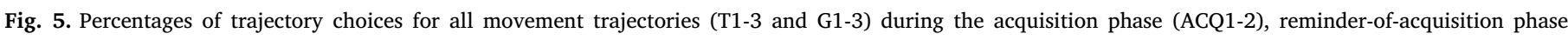
(RACQ1-2), and the generalization phase (GEN1-3) for the Experimental and Yoked Groups separately.

acquisition phase. Planned comparisons confirmed that participants in the Experimental Group still expected the painful stimulus to occur more when performing T1, compared to T2, (block1: $t(31)=2.85$, $p<.05, d=0.72$; block 2: $t(31)=4.14, p<.001, d=1.05$, and T3, (block 1: $t(31)=13.12, p<.0001, d=3.33$; block $2: t(31)=18.03$, $p<.0001, d=4.58$ ), during the reminder-of-acquisition phase. Furthermore, T2 also evoked significantly higher pain-expectancy reports, compared to T3, block 1: $t(31)=10.27, p<.0001$, $d=2.61$; block 2: $t(31)=13.89, p<.0001, d=3.53$ (see Fig. 2). No such differences emerged in the Yoked Group (all $p$-values $>.05$ ). These findings indicate that the test of generalization under extinction did not affect the acquired differential pain-expectancy ratings for the original trajectories (T1-3).

3.2.2.2. Self-reported fear of movement-related pain. A similar RM ANOVA was carried out on the fear ratings during the reminder-ofacquisition phase. There was a significant main effect of Trajectory, $F$ $(1.6,99.26)=51.41, p<.0001, \eta_{p}^{2}=0.45$, as well as a significant three-way interaction, $F(1.89,117.42)=3.78, p<.05, \eta_{p}^{2}=0.06$, suggesting that fear towards the different trajectories evolved differently within the two groups during the reminder-of-acquisition phase. Planned comparisons showed that participants in the Experimental Group were still more afraid to perform T1, (block 1: $t$ $(31)=10.49, p<.0001, d=2.66$, block $2: t(31)=13.04$, $p<.0001, d=3.31$ ) and T2, (block 1: $t(31)=9.47, p<.0001$, $d=2.41$, block $2: t(31)=11.59, p<.0001, d=2.94)$, compared to T3 (see Fig. 3). In line with the acquisition data pattern, no such differences occurred between $\mathrm{T} 1$ and $\mathrm{T} 2$ (block 1: $t(31)=1.03$, $p=.56$; block 2: $t(31)=1.45, p=.32$ ). Furthermore, no differences emerged in the Yoked Group (all $p$-values $>.05$ ). These findings show that the acquired differential fear in response to the original trajectories (T1-3) was preserved after being exposed to unreinforced generalization trajectories (G1-3).

3.2.2.3. Behavioral avoidance. A 2 x 2 RM ANOVA (Group: Experimental, Yoked) x 2 (Block: RACQ1-2) was run on the maximal deviation data during the reminder-of-acquisition phase. There was a significant main effect of Group, $F(1,62)=34.33, p<.0001, \eta_{p}^{2}$ $=0.36$, suggesting overall group differences in avoidance behavior during the reminder-of-acquisition blocks. Planned comparisons revealed that participants in the Experimental Group showed larger deviations from the shortest trajectory compared to the Yoked Group during this phase, $t(62)=5.86, p<.0001, d=1.45$. Thus, acquired avoidance behavior toward the original acquisition trajectories did not extinguish during the generalization phase (see Fig. 4).

3.2.2.4. Trajectory choice. During the first reminder-of-acquisition block, participants in the Experimental Group were 4.97 times more likely to choose $\mathrm{T} 3$ compared to $\mathrm{T} 2$ or $\mathrm{T} 1$ (or, T3 or T2 compared to T1) than participants in the Yoked Group, $\left(\exp \left(\hat{\beta}_{G}\right), p<.001\right.$; Fig. 5). 
During the second reminder-of-acquisition block, Experimental Group participants were 7.1 times more likely to choose T3 rather than T2 and $\mathrm{T} 1$ (or, $\mathrm{T} 3$ or $\mathrm{T} 2$ rather than $\mathrm{T} 1$ ) than participants in the Yoked group, $\left(\exp \left(\hat{\beta}_{\mathrm{G}}+\hat{\beta}_{\mathrm{GxB} 2}\right), p<.001\right)$. The Group x Block interaction was not significant, suggesting that the odds ratio comparing the odds of the Experimental and the Yoked Groups did not change between blocks. Thus, no additional learning occurred during the reminder-ofacquisition phase.

\subsection{Testing our main hypotheses: generalization of pain-expectancy, fear of} movement-related pain, and avoidance behavior

\subsubsection{Self-reported pain-expectancy}

A 2 × 3 × 3 RM ANOVA (Group: Experimental, Yoked) x (Block: GEN1-3) x (Trajectory: G1-3) was carried out. There was a significant main effect of Block, $F(1.85,114.65)=43.89, p<.0001, \eta_{p}^{2}=0.41$. Significant Group x Block, $F(1.85,114.65)=6.77, p<.01, \eta_{p}^{2}$ $=0.10$, and Group $\mathrm{x}$ Trajectory interactions, $F(1.38,85.73)=5.99$, $p<.01, \eta_{p}^{2}=0.09$, also emerged, suggesting that pain-expectancy changed between groups with time, and that overall pain-expectancy for the trajectories differed between groups. During the first generalization block, the Experimental Group expected the pain to occur significantly more for G1, $t(31)=2.27, p<.05, d=0.58$, and G2, $t$ $(31)=3.10, p<.01, d=0.79$, compared to G3. No significant differences occurred between G1 and G2, $t(31)=0.83, p=.41$. During the second and third generalization blocks, G2 continued to evoke higher pain-expectancy reports compared to $\mathrm{G} 3, t(31)=2.65$, $p<.05, d=0.67$, and $t(31)=2.75, p<.05, d=0.70$, respectively (see Fig. 2). During these blocks there were no differences between G1 and G2, or G1 and G3 (all $p$-values > .05). No differences occurred for any of the pairs in the Yoked Group (all $p$-values $>.05$ ).

\subsubsection{Self-reported fear of movement-related pain}

A similar RM ANOVA run on the self-reported fear in response to the generalization trajectories revealed a significant main effect of Block, $F$ $(1.71,106.30)=37.12, p<.0001, \eta_{p}^{2}=0.37$. Furthermore, significant Group x Block, $F(1.71,106.30)=5.78, p<.01, \eta_{p}^{2}=0.09$, and Group x Trajectory interactions, $F(1.42,88.03)=5.48, p<.05$, $\eta_{p}^{2}=0.08$, emerged, suggesting that fear levels changed between groups with time, and that fear for the different trajectories differed between groups. Planned comparisons revealed significantly higher fear ratings for $\mathrm{G} 1, t(31)=2.54, p<.05, d=0.65$, and G2, $t(31)=3.04$, $p<.01, d=0.77$, compared to $\mathrm{G} 3$ in the Experimental Group during the first generalization block. In line with the acquisition phase, no differences emerged between G1 and G2, $t(31)=0.51, p=1$ (see Fig. 3). The difference between G3 and G2 remained significant during the second and third blocks of the generalization phase, respectively, $t$ $(31)=2.52, p<.05, d=0.64, t(31)=3.11, p<.01, d=0.79$. However, no significant differences were observed between G1 and G3, or G1 and G2 during the rest of the generalization phase (all $p$-values $>$.05). Furthermore, no such differences occurred in the Yoked Group (all $p$-values $>.05$ ).

Together with the pain-expectancy reports, these results suggest that pain-expectancy and fear of movement-related pain initially generalized from acquisition to generalization trajectories, but decreased rapidly.

\subsubsection{Behavioral avoidance}

A 2 x 3 RM ANOVA (Group: Experimental, Yoked) x (Block: Gen1-3) was carried out. ${ }^{2}$ There was a significant main effect of Block, $F(1.88$, $116.42)=6.70, p<.01, \eta_{p}^{2}=0.10$, but not of Group, $F(1$, $62)=0.50, p=.48$, nor was there a significant Group $\mathrm{x}$ Block

\footnotetext{
${ }^{2}$ Again, trial-wise analyses were also run for the sake of completeness. These analyses did not yield differing results from the block-wise analysis.
}

interaction, $F(1.88,116.42)=0.23, p=.78, \eta_{p}^{2}=0.004$. Thus, in contrast with the verbal reports, no generalization of avoidance behavior was observed (see Fig. 4).

\subsubsection{Trajectory choice}

There was no significant effect of Group, neither was there a significant Group x Block interaction. However, a significant effect of Block emerged in the Yoked Group, whereby the odds of choosing G3 rather than G2 or G1 (or, G3 or G2 rather than G1), were 1.79 times lower for Block 2 than for Block $1\left(1 / \exp (\hat{\beta})_{\mathrm{B} 2}, p<.001\right)$. Similarly, the odds were 1.69 times lower for Block 3 than for Block 1 (1/ $\left.\left.\exp (\hat{\beta})_{\mathrm{B} 3}\right), p<.001\right)$. These results suggest that in the Yoked Group, the likelihood of choosing the avoidance trajectory decreased from the first block of the generalization phase, to the following blocks 2 and 3 of this phase.

\subsection{Exit questionnaire}

The Experimental Group retrospectively reported the resistive force of the HM to be significantly more intense compared to the Yoked Group, $t(62)=2.49, p=.02$, but after Bonferroni correction this difference was no longer significant $(p>$.007). No further differences occurred between groups on any of the other measures of the exit questionnaire (all $p$-values $>$.05). The results of this analysis are summarized in Table S2 in the supplementary materials.

\section{Discussion}

The present experiment used a sample of healthy participants, who performed an operant arm-reaching task, to test whether acquired avoidance behavior, as well as fear of movement-related pain and painexpectancy, would generalize to novel, similar movements that were never paired with pain. As expected, participants in the Experimental Group successfully acquired the experimental response-outcome contingencies. This was evidenced by pain-expectancy reports, which were highest for $\mathrm{T} 1$ (100\% reinforcement) and lowest for T3 (0\% reinforcement), with T2 (50\% reinforcement) in the middle. Furthermore, participants also learned to fear the pain-associated trajectories but not the safe trajectory, as shown by significantly higher fear of movement-related pain reported for $\mathrm{T} 1$ and $\mathrm{T} 2$ compared to T3. However, in contrast to pain-expectancy reports, participants did not show differential fear levels for the two reinforced trajectories, despite T1 and T2 having different probabilities of being followed by pain (100\% vs. $50 \%)$. We also successfully replicated acquisition of avoidance behavior (Meulders et al., 2016), as evidenced by significantly larger deviation from the shortest trajectory in the Experimental Group compared to the Yoked Group.

Second, the described acquisition effects remained present during the reminder-of-acquisition blocks, suggesting that avoidance behavior, as well as differential self-reported fear of movement-related pain and pain-expectancy towards the acquisition trajectories did not extinguish during generalization under extinction.

Third, and in line with our main hypothesis, both fear of movementrelated pain and pain-expectancy generalized to the novel, similar trajectories during the generalization phase, as shown by significantly higher self-reported fear and pain-expectancy for G1 and G2 in comparison to G3 at the beginning of the generalization phase. However, a generalization decrement was observed for both threat and safety learning. That is, there was a decrease in self-reported fear and painexpectancy from T1 to $\mathrm{G} 1(\mathrm{G} 1<\mathrm{T} 1)$ and $\mathrm{T} 2$ to $\mathrm{G} 2(\mathrm{G} 2<\mathrm{T} 2)$, whereas these increased from T3 to G3 (G3 > T3), suggesting that participants were generally less certain about the contingencies following the change from the acquisition to the generalization phase. Interestingly, in line with fear of movement-related pain reports during the acquisition phase, participants did not show differential fear- or 
pain-expectancy reports for G1 and G2. Finally, and contrary to our hypothesis, avoidance behavior did not generalize to the novel, similar movement trajectories during the generalization phase.

Some of these findings deserve further attention. First, there was a discrepancy between self-reports and the observed avoidance behavior in the generalization phase. Namely, self-reported fear of movementrelated pain and pain-expectancy generalized to the novel trajectories, whereas instrumentally acquired avoidance behavior did not. Our exploratory analyses on the trajectory choice data corroborated our findings with avoidance as a continuous measure. The lack of avoidance generalization in the current study is in contrast with previous research reporting generalization of both self-reports and operant avoidance behavior (Boyle, Roche, Dymond, \& Hermans, 2016; Cameron, Schlund, \& Dymond, 2015; Dymond, Schlund, Roche, Houwer, \& Freegard, 2012; S.; Dymond et al., 2011; Norbury, Robbins, \& Seymour, 2018; van Meurs, Wiggert, Wicker, \& Lissek, 2014). It must be noted, however, that all of these previous studies employed a simple, low-cost button press as the avoidance-response. This is a critical methodological difference from the current study, in which avoidance behavior was effortful. This seems to suggest that the generalization of operant avoidance behavior in healthy participants may depend on whether or not the avoidance-response comes at a cost.

In line with this, manipulating the cost (Van Damme, Van Ryckeghem, Wyffels, Van Hulle, \& Crombez, 2012) or value (Pittig \& Dehler, 2019) of avoidance has been found to disentangle fear and operant avoidance. Indeed, our preliminary finding of dissociated selfreports and avoidance behavior corroborates previous literature (Bravo-Rivera, Roman-Ortiz, Montesinos-Cartagena, \& Quirk, 2015; Krypotos, Effting, Kindt, \& Beckers, 2015; Meulders, 2019; Mineka, 1979; Vervliet \& Indekeu, 2015) reporting that fear and avoidance do not share a one-to-one relationship. For example, avoidance behavior is commonly found to persist even when fear has been extinguished (Bravo-Rivera et al., 2015; Mineka, 1979; Solomon, Kamin, \& Wynne, 1953; Vervliet \& Indekeu, 2015).

Avoidance behavior in real life occurs in a context with many other competing, concomitant personally valued goals (Claes, Crombez, Meulders, \& Vlaeyen, 2016; Volders, Boddez, De Peuter, Meulders, \& Vlaeyen, 2015), which may influence the relationship between fear and avoidance. For example, chronic pain patients are likely to sometimes perform valued behaviors (e.g. playing with one's children, going to work), even if they are afraid of these worsening the pain. The choice whether or not to perform a specific behavior (e.g. avoidance) often depends on the value and probability of success of each available behavioral option (Eccles \& Wigfield, 2002; Fishbach \& Ferguson, 2007). In the current study, participants had to choose between avoiding pain and avoiding effort. The Experimental Group learned that during the acquisition phase, they could successfully avoid pain by deviating from the shortest trajectory. However, the switch from the acquisition phase to the generalization phase may have decreased participants' trust in this avoidance response. Indeed, it has been suggested (Bouton, Todd, \& Leon, 2014; Bouton, Todd, Vurbic, \& Winterbauer, 2011) that during operant appetitive conditioning, a direct context-response association is produced, deeming the response less supported when the context is changed. In the present paradigm, the change from the acquisition phase to the generalization phase was operationalized by visually removing the acquisition arches and displaying the novel, intermediate generalization arches. These visual changes may have been interpreted as a context-switch (Bouton \& Todd, 2014) leading participants to believe that potentially new response-outcome contingencies would be in place. This interpretation is supported by our data, which show a clear generalization decrement for both threat- and safety learning (i.e. fear and pain-expectancy $=\mathrm{G} 1<\mathrm{T} 1, \mathrm{G} 2<\mathrm{T} 2, \mathrm{G} 3>\mathrm{T} 3$ ), suggesting a general uncertainty regarding the experimental response-outcome contingencies. This uncertainty also seems evident in the pain-expectancy reports, which differed between $\mathrm{T} 1$ and $\mathrm{T} 2$ during acquisition (T1 > T2), but did not do so between G1 and G2 during generalization
(G1 = G2). This general uncertainty regarding the experimental contingencies during the generalization phase may have decreased the perceived probability of success of the avoidance response, and increased participants' propensity to perform the less effortful movements.

However, even in this case generalization of avoidance may have occurred if participants' fear beliefs had not been disconfirmed immediately after they tested G1. Indeed, methodological characteristics may also explain the lack of generalization of avoidance behavior. For example, a perceived context-switch between the acquisition and generalization phases, due to changes in the task configuration, may have stimulated exploratory behavior. Participants may have felt more inclined to try G1 at the beginning of generalization in order to verify whether this novel trajectory, similar to the previous pain-associated trajectory, would still be paired with pain. Our data support this posthoc interpretation, as 15/32 participants in the Experimental Group chose G1 already on the first generalization trial (in comparison to 5/32 and $12 / 32$ for G2 and G3, respectively). Because of the $100 \%$ reinforcement schedule of $\mathrm{T} 1$ during acquisition, participants learned that $\mathrm{T} 1$ was always accompanied by pain. Therefore, successful generalization of avoidance from T1 to G1 would mean that participants also expected G1 to be paired with pain on a majority of trials. For example, it is possible that participants still expected G1 to be followed by pain at the beginning of the generalization phase, but due to the $100 \%$ reinforcement rate of $\mathrm{T} 1$, this expectation was immediately disconfirmed when performing a G1 movement. The change in task configuration may have functioned as an occasion setter (Baeyens et al., 2004; Holland, 1992), i.e. participants may have learned that the task configuration (the position of the arches) modulates the response-outcome contingencies. This interpretation is also in line with our results from the reminder-of-acquisition blocks, where the trajectory arches shifted back to the left, and conditioned responding returned.

Our findings of generalization in fear of movement-related pain and pain-expectancy reports are in line with previous research on operant avoidance generalization (Boyle et al., 2016; Cameron et al., 2015; Dymond et al., 2011, 2012; Norbury et al., 2018; van Meurs et al., 2014), where generalization of self-report measures was also reported. However, fear and expectancy reports declined rapidly in the current study, and only the middle (G2), but not the short (G1), generalization trajectory continued to evoke significantly higher self-reports in comparison to the "safe" generalization trajectory (G3) throughout the generalization phase. This finding parallels previous reports in the fear conditioning literature. In the current study, G2 represented an ambiguous trajectory, given that it was situated between a trajectory sometimes paired with pain (T2) and a trajectory never paired with pain (T3). Abad, Ramos-Alvarez and Rosas (Abad, Ramos-Alvarez, \& Rosas, 2009) found that a switch in contexts did not affect responding to a partially reinforced CS (ambiguous), whereas responding to a concurrently trained, continuously reinforced CS (unambiguous) decreased (Abad et al., 2009). Thus, our results are similar to those of Abad et al. (Abad et al., 2009); the change in contexts from acquisition to generalization seemed to have a greater diminishing effect on responding towards G1 than G2. As stated above, $100 \%$ reinforcement schedules often lead to a rapid decrease (e.g. extinction) of fear. Thus, to slow down the rate of extinction, partial reinforcement schedules are traditionally used in operant conditioning research (Finger, 1942; Pennes \& Ison, 1967). Given that T2 was only sometimes paired with pain during acquisition, the absence of reinforcement during G2 had a more ambiguous meaning. In contrast to this, and in line with our data, it is likely that due to the $100 \%$ reinforcement rate of $\mathrm{T} 1$, the absence of pain during G1 had a more profound meaning, and deleterious effect on fear and expectancy reports.

We observed a divergence between pain-expectancy and fear of movement-related pain measures; where pain-expectancy reports during the acquisition phase differed between all trajectories in the Experimental Group, fear of movement-related pain reports for the two 
pain-associated trajectories did not, despite differing reinforcement rates $(\mathrm{T} 1=100 \%$ vs. $\mathrm{T} 2=50 \%$ ). This divergence is in contrast to Meulders et al. (Meulders et al., 2016), where both self-report measures reflected the experimental contingencies of the acquisition phase. The current finding is, however, in line with the notion of expectancy and fear-reports reflecting different processes; namely, whereas pain-expectancy ratings have been suggested to represent a cognitive component of fear learning, and a proxy of contingency-awareness (Boddez et al., 2013), fear-reports are believed to reflect a more the emotional component of fear learning (Soeter \& Kindt, 2010). This suggests that, although participants in the current study were aware that T2 was less likely to be followed by pain than T1, the two pathways evoked similar levels of emotional (fearful) responding. Unpredictability commonly leads to increased anticipatory anxiety and physiological arousal (Carlsson et al., 2006; Davis, Walker, Miles, \& Grillon, 2010; de Berker et al., 2016; C.; Grillon, Baas, Cornwell, \& Johnson, 2006; Machida, Yang, Wellman, \& Sanford, 2013; Yoshida, Seymour, Koltzenburg, \& Dolan, 2013). Thus, despite apparent contingency awareness expressed in pain-expectancy reports, participants may have found the unpredictable pain associated with $\mathrm{T} 2$ similarly threatening as the predictable pain associated with T1.

However, this explanation only sheds light on the non-differential fear reports between $\mathrm{T} 1$ and $\mathrm{T} 2$, but not the difference in fear report results between the current study, and that of Meulders et al. (Meulders et al., 2016) (non-differential and differential fear-reports for T1 and $\mathrm{T} 2$, respectively). This finding may be explained by differences in samples. For example, the sample of Meulders et al. consisted of a majority of male participants (36 males, 14 females), whereas the current sample was mostly female ( 20 males, 42 females). Women have been found to score higher on the FPQ, and to report higher fear of pain in general (Vambheim \& Øien, 2017). In line with this, the current Experimental Group reported noticeably higher fear of pain, as measured by the FPQ (McNeil \& Rainwater, 1998; Roelofs et al., 2005) (mean FPQ: 85.63, $S D=18.31$ ), compared to that of Meulders et al. (mean FPQ: $59.56 S D=12.75$ ) (Meulders et al., 2016). Subjective fear of pain is closely linked to emotional reactions in response to the anticipation of pain (Lyby, Aslaksen, \& Flaten, 2011). Furthermore, ambiguous stimuli allow increased variance in individual responses to emerge (Lommen, Engelhard, \& van den Hout, 2010). Thus, overall higher levels of trait fear of pain in the current sample could have resulted in increased fear-reports for T2, and thus non-differential fear between $\mathrm{T} 1$ and $\mathrm{T} 2$.

Some limitations should be discussed. The current results suggest that the absence of generalization of avoidance behavior may be due to specific features in the design. First, in our study, T1 was paired with pain on $100 \%$ of trials, for reasons of replication (Meulders et al., 2016). Yet, a partial reinforcement schedule may have been better suited for investigating generalization, for reasons described above. Future research should replicate the present study with partial reinforcement rates during acquisition, to increase ambiguity, and minimize the possibility of immediate disconfirmation of participants' acquired fear beliefs. It should also be mentioned that, on closer inspection of individual response patterns, a subset of participants in the current study (4/32) did generalize avoidance. These participants chose G3 on all, or a clear majority of generalization trials, they reported higher fear for G1 and G2 compared to G3, and in the exit questionnaire they reported believing the probability of pain to follow the pattern G1 > G2 > G3. This suggests that the current paradigm has the potential to capture generalization of avoidance behavior. Given that individual differences tend to emerge with more ambiguous stimuli (Lommen et al., 2010), increasing the ambiguity of the movement trajectories in the current paradigm may increase participants' tendency to generalize avoidance behavior. Second, our results suggest that there are a variety of ways in which participants in the Experimental Group may have interpreted the change from the acquisition phase to the generalization phase (e.g. context-switch), that were not accounted for by the current design. Thus, future research should attempt to minimize the possibility of any perceived context-switch by, for example, having all trajectory arches visible throughout the entire experiment, but making explicit that only the acquisition arches can be moved through during the acquisition phase, and vice versa during the generalization phase. Finally, our sample consisted of only healthy participants, which limits the generalizability of the results to chronic pain populations. Specifically, exploratory behavior is to be expected of healthy individuals, whereas rigid behavior patterns (e.g. persistent avoidance) may be more characteristic of chronic pain patients. Indeed, cognitive and mental inflexibility has been observed in chronic pain patients both retrospectively (Karp et al., 2006; Moriarty et al., 2017), and prospectively (preceding surgery) (Attal et al., 2014). Therefore, a replication of the current study in a sample of chronic pain patients is required to further validate the paradigm and present results.

Despite these limitations, some strengths also deserve to be mentioned. First, the current data provide further support for the experimental acquisition of operant pain-related avoidance behavior in healthy participants. Second, the robotic arm-reaching paradigm offers increased ecological validity for the investigation of avoidance behavior in comparison to traditional avoidance paradigms, because it enables participants to acquire a costly avoidance response instead of simply performing an arbitrary, low-cost avoidance response, instructed by the experimenter. Exploratory analyses of avoidance as trajectory choice behavior corroborated our findings with avoidance behavior as a continuous measure, further adding to the validity of the paradigm. Furthermore, traditional avoidance paradigms in the anxiety literature usually only measure adaptive avoidance, given that the avoidanceresponse, such as a button press, effectively cancels the aversive stimulus. In contrast, the current paradigm provides a means to investigate maladaptive avoidance, because performing G3 requires more effort than was previously needed to completely avoid pain, thus representing overgeneralization. To our best knowledge, the current study is the first to investigate avoidance generalization using such a paradigm, and thus offers novel preliminary data on the mechanisms possibly underlying avoidance generalization in healthy humans.

In conclusion, the present study demonstrates that fear and painexpectancies can generalize even in the absence of overt avoidance behavior. These findings add to a growing literature suggesting that pain-related avoidance behavior and pain-related fear may not always share a direct relationship. Instead, at least in healthy participants, this relationship can be affected by such factors as the effort required to perform an avoidance response; when avoidance behavior is effortful, healthy people may be more likely to explore other behavioral options, especially so when the effectiveness of avoidance is not certain. Given the crucial role avoidance behavior plays in disability, the generalization of pain-related avoidance remains and interesting topic of investigation, and potential pathway into the development and maintenance of chronic pain.

\section{Declaration of competing interest}

The authors report no conflict of interest.

\section{Acknowledgments}

This research is supported by a Vidi grant from the Netherlands Organization for Scientific Research (NWO), The Netherlands (grant ID 452-17-002) granted to Ann Meulders. Ann Meulders is also a postdoctoral researcher of the Research Foundation Flanders (FWOVlaanderen), Belgium (grant ID: 12E3717N). The authors report no conflict of interest.

The authors wish to thank Jacco Ronner for programming the experiment and Richard Benning for designing and creating the graphics of the experiment. 


\section{Appendix A. Supplementary data}

Supplementary data to this article can be found online at https:// doi.org/10.1016/j.brat.2019.103525.

\section{References}

Abad, M. J., Ramos-Alvarez, M. M., \& Rosas, J. M. (2009). Partial reinforcement and context switch effects in human predictive learning. The Quarterly Journal of Experimental Psychology, 62(1), 174-188. https://doi.org/10.1080/ 17470210701855561.

Attal, N., Masselin-Dubois, A., Martinez, V., Jayr, C., Albi, A., Fermanian, J., ... Baudic, S. (2014). Does cognitive functioning predict chronic pain? Results from a prospective surgical cohort. Brain, 137(3), 904-917. https://doi.org/10.1093/brain/awt354.

Baeyens, F., Vervliet, B., Vansteenwegen, D., Beckers, T., Hermans, D., \& Eelen, P. (2004). Simultaneous and sequential Feature Negative discriminations: Elemental learning and occasion setting in human Pavlovian conditioning. Learning and Motivation, 35(2), 136-166. https://doi.org/10.1016/S0023-9690(03)00058-4.

de Berker, A. O., Rutledge, R. B., Mathys, C., Marshall, L., Cross, G. F., Dolan, R. J., et al. (2016). Computations of uncertainty mediate acute stress responses in humans. Nature Communications, 7, 10996. https://doi.org/10.1038/ncomms10996.

Boddez, Y., Baeyens, F., Luyten, L., Vansteenwegen, D., Hermans, D., \& Beckers, T. (2013). Rating data are underrated: Validity of US expectancy in human fear conditioning. Journal of Behavior Therapy and Experimental Psychiatry, 44(2), 201-206. https://doi.org/10.1016/j.jbtep.2012.08.003.

Bouton, M. E., \& Todd, T. P. (2014a). A fundamental role for context in instrumental learning and extinction. Behavioural Processes, 104, 13-19. https://doi.org/10.1016/ j.beproc.2014.02.012.

Bouton, M. E., Todd, T. P., \& Leon, S. P. (2014b). Contextual control of discriminated operant behavior. Journal of Experimental Psychology: Animal Learning and Cognition, 40(1), 92-105. https://doi.org/10.1037/xan0000002.

Bouton, M. E., Todd, T. P., Vurbic, D., \& Winterbauer, N. E. (2011). Renewal after the extinction of free operant behavior. Learning \& Behavior, 39(1), 57-67. https://doi. org/10.3758/s13420-011-0018-6.

Boyle, S., Roche, B., Dymond, S., \& Hermans, D. (2016). Generalisation of fear and avoidance along a semantic continuum. Cognition \& Emotion, 30(2), 340-352. https:// doi.org/10.1080/02699931.2014.1000831.

Bravo-Rivera, C., Roman-Ortiz, C., Montesinos-Cartagena, M., \& Quirk, G. J. (2015). Persistent active avoidance correlates with activity in prelimbic cortex and ventral striatum. Frontiers in Behavioral Neuroscience, 9. https://doi.org/10.3389/fnbeh.2015. 00184 184-184.

Breivik, H., Collett, B., Ventafridda, V., Cohen, R., \& Gallacher, D. (2006). Survey of chronic pain in europe: Prevalence, impact on daily life, and treatment. European Journal of Pain, 10(4), 287-333.

Breivik, H., Eisenberg, E., O'Brien, T., \& Openminds (2013). The individual and societal burden of chronic pain in europe: The case for strategic prioritisation and action to improve knowledge and availability of appropriate care. BMC Public Health, 13. https://doi.org/10.1186/1471-2458-13-1229 1229-1229.

Cameron, G., Schlund, M. W., \& Dymond, S. (2015). Generalization of socially transmitted and instructed avoidance. Frontiers in Behavioral Neuroscience, 9(159), https:// doi.org/10.3389/fnbeh.2015.00159.

Carlsson, K., Andersson, J., Petrovic, P., Petersson, K. M., Ohman, A., \& Ingvar, M. (2006). Predictability modulates the affective and sensory-discriminative neural processing of pain. NeuroImage, 32(4), 1804-1814. https://doi.org/10.1016/j.neuroimage.2006. 05.027.

Claes, N., Crombez, G., Meulders, A., \& Vlaeyen, J. W. (2016). Between the devil and the deep blue sea: Avoidance-avoidance competition increases pain-related fear and slows decision-making. The Journal of Pain, 17(4), 424-435. https://doi.org/10. 1016/j.jpain.2015.12.005.

Crombez, G., Eccleston, C., Van Damme, S., Vlaeyen, J. W., \& Karoly, P. (2012). Fearavoidance model of chronic pain: The next generation. The Clinical Journal of Pain 28(6), 475-483. https://doi.org/10.1097/AJP.0b013e3182385392.

Davis, M., Walker, D. L., Miles, L., \& Grillon, C. (2010). Phasic vs sustained fear in rats and humans: Role of the extended amygdala in fear vs anxiety. Neuropsychopharmacology, 35(1), 105-135. https://doi.org/10.1038/npp.2009.109.

Dunsmoor, J. E., Mitroff, S. R., \& LaBar, K. S. (2009). Generalization of conditioned fear along a dimension of increasing fear intensity. Learning \& Memory, 16(7), 460-469. https://doi.org/10.1101/lm.1431609.

Dunsmoor, J. E., Prince, S. E., Murty, V. P., Kragel, P. A., \& LaBar, K. S. (2011). Neurobehavioral mechanisms of human fear generalization. NeuroImage, 55(4), 1878-1888. https://doi.org/10.1016/j.neuroimage.2011.01.041.

Dymond, S., Roche, Houwer, D., \& Freegard (2012). Safe from harm: Learned, instructed, and symbolic generalization pathways of human threat-avoidance. PLoS One, 7(10), https://doi.org/10.1371/journal.pone.0047539.

Dymond, S., Schlund, M. W., Roche, B., Whelan, R., Richards, J., \& Davies, C. (2011a). Inferred threat and safety: Symbolic generalization of human avoidance learning. Behaviour Research and Therapy, 49(10), 614-621. https://doi.org/10.1016/j.brat. 2011.06.007.

Dymond, D., Vervliet, R., \& Hermans (2015). Fear generalization in humans: Systematic review and implications for anxiety disorder research. Behavior Therapy, 46(5), 561-582. https://doi.org/10.1016/j.beth.2014.10.001.

Dymond, S., Whelan, R., Richards, \& Davies (2011b). Inferred threat and safety: Symbolic generalization of human avoidance learning. Behaviour Research and Therapy, 49(10), 614-621. https://doi.org/10.1016/j.brat.2011.06.007.
Eccles, J. S., \& Wigfield, A. (2002). Motivational beliefs, values, and goals. Annual Review of Psychology, 53(1), 109-132. https://doi.org/10.1146/annurev.psych.53.100901. 135153.

Engelen, U., Peuter, S. D., Victoir, A., Diest, I. V., \& Van den Bergh, O. (2006). Verdere validering van de Positive and Negative Affect Schedule (PANAS) en vergelijking van twee Nederlandstalige versies. Gedrag \& Gezondheid, 34(2), 61-70. https://doi.org/ 10.1007/bf03087979.

Finger, F. W. (1942). Retention and subsequent extinction of a simple running response following varying conditions of reinforcement. Journal of Experimental Psychology, 31(2), 120-133. https://doi.org/10.1037/h0055418.

Fishbach, A., \& Ferguson, M. J. (2007). The goal construct in social psychology. Social psychology: Handbook of basic principles (pp. 490-515). (2nd ed.). New York, NY, US: The Guilford Press.

Gamez, W., Chmielewski, M., Kotov, R., Ruggero, C., \& Watson, D. (2011). Development of a measure of experiential avoidance: The multidimensional experiential avoidance questionnaire. Psychological Assessment, 23(3), 692-713. https://doi.org/10.1037/ a0023242.

Gaskin, D. J., \& Richard, P. (2012). The economic costs of pain in the United States. The Journal of Pain, 13(8), 715-724. https://doi.org/10.1016/j.jpain.2012.03.009.

Ghirlanda, S., \& Enquist, M. (2003). A century of generalization. Animal Behaviour, 66(1), $15-36$.

Greenberg, T., Carlson, J. M., Cha, J., Hajcak, G., \& Mujica-Parodi, L. R. (2013). Neural reactivity tracks fear generalization gradients. Biological Psychology, 92(1), 2-8. https://doi.org/10.1016/j.biopsycho.2011.12.007.

Grillon, C., Baas, J. M., Cornwell, B., \& Johnson, L. (2006). Context conditioning and behavioral avoidance in a virtual reality environment: Effect of predictability. Biological Psychiatry, 60(7), 752-759. https://doi.org/10.1016/j.biopsych.2006.03. 072.

Grillon, C., Bradford, D. E., Burton, P., Reynolds, R. C., Alvarez, R. P., Lissek, S., et al. (2013). Neural substrates of classically conditioned fear-generalization in humans: A parametric fMRI study. Social Cognitive and Affective Neuroscience, 9(8), 1134-1142. https://doi.org/10.1093/scan/nst096.

Holland, P. C. (1992). Occasion setting in pavlovian conditioning. In D. L. Medin (Vol. Ed.), Psychology of learning and motivation: Vol.28, (pp. 69-125). Academic Press.

Honig, W. K., \& Urcuioli, P. J. (1981). The legacy of Guttman and Kalish (1956): Twentyfive years of research on stimulus generalization. Journal of the Experimental Analysis of Behavior, 36(3), 405-445.

IOM (Institute of Medicine)., \& Institute of Medicine (US) Committee on Advancing Pain Research, Care, and Education. (2011). Relieving pain in America: A blueprint for transforming prevention, care, education, and research. Washington (DC): National Academies Press (US) National Academy of Sciences.

Kalish, H. I. (1969). Stimulus generalization. In M. M. A. H (Ed.). Learning processes (pp. 207-297). Oxford, England: Macmillan.

Karp, J. F., Reynolds, C. F., Butters, M. A., Dew, M. A., Mazumdar, S., Begley, A. E., ... Weiner, D. K. (2006). The relationship between pain and mental flexibility in older adult pain clinic patients. Pain Medicine, 7(5), 444-452. https://doi.org/10.1111/j. 1526-4637.2006.00212.x.

Krypotos, A. M., Effting, M., Kindt, M., \& Beckers, T. (2015). Avoidance learning: A review of theoretical models and recent developments. Frontiers in Behavioral Neuroscience, 9, 189. https://doi.org/10.3389/fnbeh.2015.00189.

Krypotos, A. M., Vervliet, B., \& Engelhard, I. M. (2018). The validity of human avoidance paradigms. Behaviour Research and Therapy, 111, 99-105. https://doi.org/10.1016/j. brat.2018.10.011.

Leeuw, M., Goossens, M. E., Linton, S. J., Crombez, G., Boersma, K., \& Vlaeyen, J. W. (2007). The fear-avoidance model of musculoskeletal pain: Current state of scientific evidence. Journal of Behavioral Medicine, 30(1), 77-94. https://doi.org/10.1007/ s10865-006-9085-0.

Lissek, S., Biggs, A. L., Rabin, S. J., Cornwell, B. R., Alvarez, R. P., Pine, D. S., et al. (2008). Generalization of conditioned fear-potentiated startle in humans: Experimental validation and clinical relevance. Behaviour Research and Therapy, 46(5), 678-687. https://doi.org/10.1016/j.brat.2008.02.005.

Lissek, S., \& Grillon, C. (2010). Overgeneralization of conditioned fear in the anxiety disorders. Zeitschrift für Psychologie/Journal of Psychology, 218(2), 146-148.

Lommen, M. J. J., Engelhard, I. M., \& van den Hout, M. A. (2010). Neuroticism and avoidance of ambiguous stimuli: Better safe than sorry? Personality and Individual Differences, 49(8), 1001-1006. https://doi.org/10.1016/j.paid.2010.08.012.

Lyby, P. S., Aslaksen, P. M., \& Flaten, M. A. (2011). Variability in placebo analgesia and the role of fear of pain-an ERP study. Pain, 152(10), 2405-2412. https://doi.org/10. 1016/j.pain.2011.07.010.

Machida, M., Yang, L., Wellman, L. L., \& Sanford, L. D. (2013). Effects of stressor predictability on escape learning and sleep in mice. Sleep, 36(3), 421-430. https://doi. org/10.5665/sleep.2464.

McNeil, D. W., \& Rainwater, A. J. (1998). Development of the fear of pain questionnaireIII. Journal of Behavioral Medicine, 21(4), 389-410.

Meulders (2019). From fear of movement-related pain and avoidance to chronic pain disability: A state-of-the-art review. Current Opinion in Behavioral Sciences, 26, 130-136. https://doi.org/10.1016/j.cobeha.2018.12.007.

Meulders, Franssen, Fonteyne, \& Vlaeyen (2016). Acquisition and extinction of operant pain-related avoidance behavior using a 3 degrees-of-freedom robotic arm. Pain, 157(5), 1094-1104. https://doi.org/10.1097/j.pain.0000000000000483.

Meulders, Harvie, B., Caragianis, V., \& Moseley (2014). Contingency learning deficits and generalization in chronic unilateral hand pain patients. The Journal of Pain, 15(10), 1046-1056. https://doi.org/10.1016/j.jpain.2014.07.005.

Meulders, Jans, \& Vlaeyen (2015). Differences in pain-related fear acquisition and generalization: An experimental study comparing patients with fibromyalgia and healthy controls. Pain, 156(1), 108-122. https://doi.org/10.1016/j.pain. 
0000000000000016.

Meulders, Vandebroek, Vervliet, \& Vlaeyen (2013). Generalization gradients in cued and contextual pain-related fear: An experimental study in healthy participants. Frontiers in Human Neuroscience, 7. https://doi.org/10.3389/fnhum.2013.00345.

Meulders, Vansteenwegen, \& Vlaeyen (2011). The acquisition of fear of movement-related pain and associative learning: A novel pain-relevant human fear conditioning paradigm. Pain, 152(11), 2460-2469. https://doi.org/10.1016/j.pain.2011.05.015.

Meulders, \& Vlaeyen (2013). The acquisition and generalization of cued and contextua pain-related fear: An experimental study using a voluntary movement paradigm. Pain, 154(2), 272-282. https://doi.org/10.1016/j.pain.2012.10.025.

van Meurs, B., Wiggert, N., Wicker, I., \& Lissek, S. (2014). Maladaptive behavioral consequences of conditioned fear-generalization: A pronounced, yet sparsely studied, feature of anxiety pathology. Behaviour Research and Therapy, 57, 29-37. https://doi. org/10.1016/j.brat.2014.03.009.

Mineka, S. (1979). The role of fear in theories of avoidance learning, flooding, and extinction. Psychological Bulletin, 86(5), 985-1010. https://doi.org/10.1037/00332909.86.5.985.

Moriarty, O., Ruane, N., O'Gorman, D., Maharaj, C. H., Mitchell, C., Sarma, K. M., ... McGuire, B. E. (2017). Cognitive impairment in patients with chronic neuropathic or radicular pain: An interaction of pain and age. Frontiers in Behavioral Neuroscience, 11(100), https://doi.org/10.3389/fnbeh.2017.00100.

Norbury, A., Robbins, T. W., \& Seymour, B. (2018). Value generalization in human avoidance learning. Elife, 7. https://doi.org/10.7554/eLife.34779.

Pennes, E. S., \& Ison, J. R. (1967). Effects of partial reinforcement on discrimination learning and subsequent reversal or extinction. Journal of Experimental Psychology, 74(2), 219-224. https://doi.org/10.1037/h0024631 Pt.1.

Phillips, C. J. (2009). The cost and burden of chronic pain. Reviews in pain, 3(1), 2-5. https://doi.org/10.1177/204946370900300102.

Pittig, A., \& Dehler, J. (2019). Same fear responses, less avoidance: Rewards competing with aversive outcomes do not buffer fear acquisition, but attenuate avoidance to accelerate subsequent fear extinction. Behaviour Research and Therapy, 112, 1-11. https://doi.org/10.1016/j.brat.2018.11.003.

Roelofs, J., Peters, M. L., Deutz, J., Spijker, C., \& Vlaeyen, J. W. (2005). The fear of pain questionnaire (FPQ): Further psychometric examination in a non-clinical sample. Pain, 116(3), 339-346. https://doi.org/10.1016/j.pain.2005.05.003.

Simons, J. S., \& Gaher, R. M. (2005). The distress tolerance scale: Development and validation of a self-report measure. Motivation and Emotion, 29(2), 83-102. https://doi. org/10.1007/s11031-005-7955-3.
Skinner, B. F. (1953). Science and human behavior. Simon and Schuster.

Soeter, M., \& Kindt, M. (2010). Dissociating response systems: Erasing fear from memory. Neurobiology of Learning and Memory, 94(1), 30-41. https://doi.org/10.1016/j.nlm. 2010.03.004.

Solomon, R. L., Kamin, L. J., \& Wynne, L. C. (1953). Traumatic avoidance learning: The outcomes of several extinction procedures with dogs. Journal of Abnormal and Social Psychology, 48(2), 291-302. https://doi.org/10.1037/h0058943.

Sullivan, M. J., Bishop, S. R., \& Pivik, J. (1995). The pain catastrophizing scale: Development and validation. Psychological Assessment, 7(4), 524.

Treede, R.-D., Rief, W., Barke, A., Aziz, Q., Bennett, M. I., Benoliel, R., \& Wang, S.-J. (2015). A classification of chronic pain for ICD-11. Pain, 156(6), 1003-1007. https:// doi.org/10.1097/j.pain.0000000000000160.

Vambheim, S. M., \& Øien, R. A. (2017). Sex differences in fear of pain: Item-level analysis of the fear of pain questionnaire III. Journal of Pain Research, 10, 825-831. https:// doi.org/10.2147/JPR.S128850.

Van Damme, S., Van Ryckeghem, D. M., Wyffels, F., Van Hulle, L., \& Crombez, G. (2012). No pain no gain? Pursuing a competing goal inhibits avoidance behavior. Pain, 153(4), 800-804. https://doi.org/10.1016/j.pain.2011.12.015.

Vervliet, B., \& Indekeu, E. (2015). Low-cost avoidance behaviors are resistant to fear extinction in humans. Frontiers in Behavioral Neuroscience, 9, 351. https://doi.org/10 3389/fnbeh.2015.00351.

Vlaeyen (2015). Learning to predict and control harmful events: Chronic pain and conditioning. Pain, 156(Suppl 1), S86-S93. https://doi.org/10.1097/j.pain. 0000000000000107.

Vlaeyen, \& Linton (2000). Fear-avoidance and its consequences in chronic musculoskeletal pain: A state of the art. Pain, 85(3), 317-332.

Vlaeyen, \& Linton (2012). Fear-avoidance model of chronic musculoskeletal pain: 12 years on. Pain, 153(6), 1144-1147. https://doi.org/10.1016/j.pain.2011.12.009.

Volders, S., Boddez, Y., De Peuter, S., Meulders, A., \& Vlaeyen, J. W. (2015). Avoidance behavior in chronic pain research: A cold case revisited. Behaviour Research and Therapy, 64, 31-37. https://doi.org/10.1016/j.brat.2014.11.003.

Watson, D., Clark, L. A., \& Tellegen, A. (1988). Development and validation of brief measures of positive and negative affect: The PANAS scales. Journal of Personality and Social Psychology, 54(6), 1063.

Yoshida, W., Seymour, B., Koltzenburg, M., \& Dolan, R. J. (2013). Uncertainty increases pain: Evidence for a novel mechanism of pain modulation involving the periaqueductal gray. Journal of Neuroscience, 33(13), 5638-5646. https://doi.org/10.1523/ jneurosci.4984-12.2013. 